\title{
BIM EXTENSION FOR SUSTAINABILITY APPRAISAL OF CONCEPTUAL STEEL DESIGN
}

\begin{abstract}
Contemporary advancements in Information Technology and the efforts from various research initiatives in the AEC industry are showing evidence of progress with the emergence of building information modelling (BIM). BIM presents the opportunity of electronically modelling and managing the vast amount of information embedded in a building project, from its conception to end-of-life. Researchers have been looking at extensions to expand its scope. Sustainability is one such modelling extension that is in need of development. This is becoming pertinent for the structural engineer as recent design criteria have put great emphasis on the sustainability credentials in addition to the traditional criteria of structural integrity, constructability and cost. With the complexity of designs, there are now needs to provide decision support tools to aid in the assessment of the sustainability credentials of design solutions. Such tools would be most beneficial at the conceptual design stage so that sustainability is built into the design solution starting from its inception. The sustainability of buildings is related to life cycle and is measured using indicatorterms such as life cycle costing, ecological footprint and carbon footprint. This paper proposes a modelling framework combining these three indicators in providing sustainability assessments of alternative design solutions based on the economic and environmental sustainability pillars. It employs the principles of feature-based modelling to extract construction-specific information from product models for the purposes of sustainability analysis. A prototype system is implemented using .NET and linked to the BIM enabled software, Revit Structures ${ }^{\mathrm{TM}}$. The system appraises alternative design solutions using multicriteria performance analysis. This work demonstrates that current process and data modelling techniques can be employed to model sustainability related information to inform decisions right from the early stages of structural design. It concludes that the utilized information modelling representations - in the form of a process model, implementation algorithms and object-based instantiations - can capture sustainability related information to inform decisions at the early stages of the structural design process.
\end{abstract}

Keywords: sustainability, BIM extension, conceptual design, feature-based modelling

\section{INTRODUCTION}

The design stage presents the best opportunity to influence cost and sustainability impacts covering the whole life cycle stages of a building [1,2]. This makes targeting the design stage very important for incorporating building performance issues such as sustainability. The situation therefore creates demand on the development of decision support tools to guide designers in the early design stage when changes can easily be accommodated with very minimal consequences. The result is that such demands become additional challenges to the already existing goal of capturing the building product in a single information model. These challenges still exist with the newly emerging BIM, although with improved opportunities for expansion and extension to capture the vast amount of information related to various AEC domains. In the structural engineering domain, sustainability decision support tools for guiding engineers in early design iterations have not been sufficiently explored. This work presents a modelling framework aimed at incorporating sustainability measures to inform the conceptual design process of steel-framed buildings 
using principles of feature-based modelling. It proposes the use of life cycle approach to explore cost, as well as carbon and ecological footprint. The intention of this work is to provide a BIM integrated system that will aid structural engineers to assess the sustainability measures of alternative design solutions from the early stages of design. This is new in the structural engineering domain and it has not been considered as an assessment approach, with respect to profession-specific considerations, in existing building sustainability appraisal tools.

This paper is presented in five sections; summarized as introduction, background, prototype implementation, implementation features significance and conclusion. It highlights information modelling challenges associated with sustainability assessment and gives a background on existing BIM extensions in modelling aspects of the building. The paper presents the implementation of a proposed prototype system for sustainability appraisal with a discussion of its significance in expanding the scope of building information modelling applications.

\subsection{Challenges with assessing building sustainability}

Uher [3] identified the development of key principles/indicators as one of the main areas of research in sustainable construction. He suggested energy consumption and land used for building as two ideal absolute indicators. This is based on the premise that construction works are highly energy intensive and land is always required for expansion to accommodate construction activities and products. However, the implementation and strategy for employing such indicators in assessing sustainability at the design stage was not addressed and, in the authors' opinion, remains a challenge. In a more recent report on strategy for BIM adoption and management, whole life cost and carbon performance were identified as the key variables that can influence building sustainability performance significantly [4]. Notwithstanding, the contemporary progress made in the development of tools for building's environmental performance assessment is worth mentioning despite their inadequacy of being used for sustainability assessment [5]. Quite a number of countries have developed building environmental performance assessment tools tailored to their local conditions. Some of these tools also have the potential of being applied internationally as reviewed in $[2,5]$. The tools have been classified into three groups: product comparison; decision support and whole building framework. The more widely used tools such as - Building Research Establishment Environmental Assessment Method (BREEAM) and Leadership in Energy and Environmental Design (LEED), developed in the UK and USA respectively, belong to the whole building framework category. This category is more comprehensive in application than other two.

While recognising the advances made in developing building environmental performance assessment tools, there have also been some criticism warranting further research. In addition to complexity and regional variations, Ding [2] hinged the development of a sustainability index on the critique that these tools are difficult to apply at the early project phases and largely ignore the economic aspect of sustainability. Haapio and Viitaniemi [5] also pointed out the difficulty with subjectivity in indicator assessment from the user's point of view - as architects and engineers may consider indicators differently. In the authors' opinion, this triggers an interesting point: all building professionals ought to be responsible for the information on the sustainability performance of their design specifications as they do for the integrity of their designs. This premise remains a key motivation for this research.

Limitations also exist on issues pertaining data used in the assessment of building sustainability. Systems that generate life cycle process of materials are based on different criteria such as boundary conditions and often produce conflicting life cycle analysis results. As such, the quality of secondary data accessible to dependent systems is always an issue to adequately address. Even with the availability of secondary data from existing databases, information are not yet comprehensive enough to cover numerous materials comprising the building artefact. It results in the use of assumptions to ease system limitations as evident in [6] where, among others, an average weight per unit area has been assumed for copper wiring in commercial buildings in carrying out life cycle energy and environmental performance of a new building. Sustainability assessment concerning the environment is hinged on life cycle analysis (LCA) which has been noted to be a source of contention and uncertainties in building assessment. The uncertainties beclouding LCA process have been largely attributed to the lack in the availability of quality data and remain a critical problem requiring special attention [7]. 


\subsection{Research problem}

Besides the challenges associated with defining and quantifying sustainability in the built environment, current sustainability assessments have been based on the completed structure. This apparently compromises the usefulness of sustainability ratings in design-decisions making process. The need is therefore to establish quantitative terms for qualifying sustainability and incorporating it right at the early stages of the project development process to guide decisions as progress is made. Owing to the inherent traditional fragmentation of the industry, it is only logical that various professional platforms think along the lines of their particular responsibilities in the project process. This will create a possibility for collaboratively unifying the different platform-based sustainability ratings at salient project stages. For the structural engineer, tools dedicated to depicting sustainability to inform design-decisions on options are generally lacking. This research work is therefore aimed at using process and data modelling techniques to assess the sustainability of the structural engineer's building design options. As an initiation, this work is directed at modelling the sustainability of steel-framed buildings to inform engineers during conceptual design activity in contemporary BIM environments. The same approach could be used for other forms of construction.

\section{BACKGROUND}

The fragmented nature of the AEC industry is linked to the complex and unique nature of the building product which requires the participation of individual/groups from distinct professional platforms. These professional platforms, however, are not independent as their specifications and designs must accommodate, interact and relate with one another throughout the building's lifecycle. The drive for effectiveness and efficiency in managing the inter-dependence among the platform has given rise to principles such as concurrent engineering, collaborative engineering, distributive collaboration etc. in the AEC industry. In all these, IT plays the key role of being the kernel for modelling, storing, exchanging information/data within and across platforms. The role of international standards, open formats and product models such as Industry Foundation Classes (IFC) and Green Building XML (gbXML) in enhancing the management of information in the industry cannot be over-emphasized. In overcoming the associated shortcomings with AEC information management, researchers, have had the vision of capturing all the information embedded in the building product in a single information model. Even with the evolution of BIM, embodying parametric objects governed by rules of geometry, attributes and relations; this vision is yet to be fully realized. The inclusion and accessibility of other design information such as cost estimation, selection of construction methods, construction scheduling, productivity analysis and project management associated with various construction practitioners still need tackling [8].

\subsection{BIM extensions}

$\mathrm{BIM}$ is becoming conversant in the AEC Industry because of the international campaign for its adoption in project execution. It is said to represent the next generation of IT which will involve processes of generating, storing, managing, exchanging and sharing of building information in an interoperable and reusable way [9]. Though the scope is yet to be fully defined [10], its benefits in project implementation and information management are envisaged to be significant. BIM has the tendencies for continuous expansion to closely mimic the vast amount of information embedded in typical building project. Thus, the possibility of expanding the BIM scope has already been demonstrated by researchers in various plausible extensions. BIM extensions in this paper, refers to new software systems that add additional functionality to BIM-enable tools through add-on applications such as application programming interface (API). An example is the multi-dimensional computer model (3D to $\mathrm{nD}$ modelling project) [11]. The project aims to facilitate the integration of time, cost, accessibility, sustainability, maintainability, acoustics, crime and thermal requirement into the modeling of building information. Modeling $\mathrm{nD}$ aspects is demanding and involves extending the building information model to incorporate the various building life cycle design information. This warrants an issue-specific approach; hence researchers have begun 
tackling specific aspects or components. In the construction stage of the building lifecycle, efforts to fuse 4D technology (construction scheduling) with BIM for better construction performance are also underway [12]. Disaster preparedness aspect in the building operation phase is geared towards improving training games by modelling hot dynamic conditions and the building behaviour over time in the event of fire [13, 14]. The implementation of fall protection using automated rule-based checking system for BIM is another area of safety planning during construction that has been proposed by Zhang et al [15]

The reality of adopting BIM for construction transaction appears to be getting clearer as time progresses. Besides incentives from implementation targets set by institutions [4], there has been growing research on different facets of BIM implementation. Among the lot to keep up with, selected few are further mentioned here. Tang et al [16] are looking at the direction of using laser scanners to create asbuilt BIM to capture the difference from its as-design BIM counterpart. Although the authors acknowledge the existence huge knowledge gap, the success of this research could benefit the creation of as-built BIM for existing building stock of ages ago. The maintenance of the building stock could also be eased with BIM applications that learn from maintenance history [17]. There is also the possibility of using BIM to design and plan scaffolding systems for maintenance and other construction activities [18]. Finally to enhance research focus and directions, there have been efforts to establish a well-rounded BIM application framework on the utilization of BIM throughout the life-cycle of facilities with the intention to emphasize the importance of BIM to stakeholders who may think otherwise. The framework groups BIM applications into three parts: all project management domains, all stakeholders, and across the whole project lifecycle. Where an application of BIM is defined to cover processes that expands 3D computable data into an $\mathrm{nD}$ information model allowing dynamic and virtual analysis of scheduling, costing, stability, sustainability, maintainability, evacuation simulation and safety etc. [19].

In the planning and design stage, the benefits of the early incorporation of sustainability principles in guiding project decisions and design iterations have been well emphasized [1]. One area of challenge has been the development of sustainability appraisal tools to guide professionals in making conceptual design decisions among alternative solutions. Although a number of sustainability assessment tools exist, it has been difficult for engineers to apply them to conceptual design iterations via the emerging BIM process. The Building Research Establishment Environmental Assessment Method (BREEAM), used in the UK, is yet to be incorporated into BIM. It is currently being used to guide project development and to rank already completed buildings. In the US, research efforts to incorporate Leadership in Energy and Environmental Design (LEED) criteria into BIM tools have been on-going. Nguyen et al [20] has attempted to use BIM to evaluate sustainability of architectural designs by storing the LEED criteria indicators as project parameters in Revit Architecture software. These parameters are extracted when applied to a project to compute the maximum possible LEED ratings. While this work targets architectural designs, it is limited to the LEED sustainability parameters and will not be of direct benefit to the structural engineer's conceptual design iterations.

\subsection{The modelling of design-specific sustainability information}

In an effort to improve the usability of BIM with respect to extracting and querying construction-specific information, Nepal [21] employed the feature-based modelling (see Figure 1) approach to develop feature ontology to aid recognition of building features. A feature is an information unit or element representing a region of interest within a product [22] and has also been described as a component making up a model $[23,24]$. Models may be enhanced by the use of existing information to produce new information, change product information, extract portions of the model or add some new information to it $[25,26]$. Similarly, the estimation of construction activity production rates have been enhanced using project history and contextual information from as-planned and as built project models[27]. Feature-based modelling (FBM) has its root in mechanical engineering for integrating Computer Aided Drafting (CAD) and Computer Aided Manufacturing (CAM) systems [28-30]. Two key requirements of FBM systems are extensibility and flexibility which typically characterize the dynamic nature of design [31]. Previous work $[31,32]$ on applying FBM in AEC has given an industry-adapted (architecture) definition of features as " $a$ collection of high-level information defining a set of characteristics or concepts with a semantic meaning to a particular view in the life-cycle of a building". This provides a take-off point for modelling buildings structural-specific sustainability information that can inform the conceptual design process. Brunetti and 
Golob [22] recognized the highly complex informal data characterising conceptual design and have proposed using FBM principles in incorporating the representation of conceptual design information into the development process of an integrated product model. However, it is yet to be applied to sustainability information modelling to the benefit of the structural engineer's conceptual design iteration.

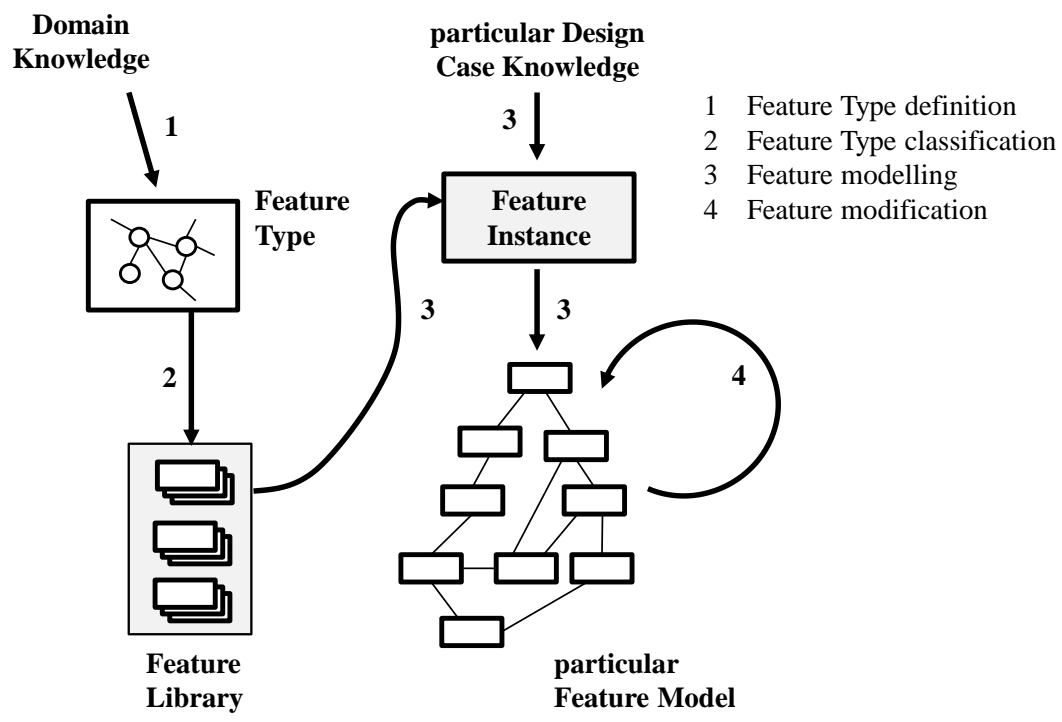

Figure 1: Activities in feature based modelling [32]

Three approaches have been identified in FBM; design-by-features, feature recognition and a hybrid of both [32]. Design-by-feature develops designs from high level features generated from primitives and/or user-defined features embodying design intents largely based on geometry. In feature recognition approach, as the name implies, features are extracted from already designed artefacts based on recognition (data interpretation and analysis by computer algorithms or user) to build a feature model. Feature recognition has been applied in this research to extract relevant structural domain information from a product model (BIM) for the purpose of performing sustainability analysis. Details of the representations of the four key activities of feature type definition, classification, modelling and modification applied in this research have been discussed in [33] and are briefly described in Section 3.3.

\section{IMPLEMENTATION OF SUSTAINABILITY MODELLING PROTOYPE}

This section presents the sustainability modelling framework and its implementation. It briefly discusses the basis for the utilized sustainability indicator measures, the system implementation requirements, components of the framework and how the various constituent objects relate in the operation of the model. A case-illustration of the prototype is also included in this section.

\subsection{Sustainability parameters}

Researchers have mentioned the need to develop sustainability indicators that could be applied worldwide $[34,35]$. It is essential for such indicators to mimic the essence of the sustainable development concept of economic, environmental and the social pillars [36]. However, the methodologies to accounting for the social aspect of sustainability are not fully developed [37] and social issues do not significantly influence structural conceptual design process of steel-framed buildings. Thus, the overall social benefits of projects would have been clearly defined from the onset and have minimal effect on structural design decisions. The proposed modelling framework therefore reflects the economic and environmental aspects of sustainability of steel framed buildings. Life cycle costing technique is used to account for economic sustainability and a combination of carbon footprint and ecological footprint indicators to account for environmental sustainability. The theories and background surrounding the use of these indicators have 
been discussed in [38] as such key aspects are given here. The life cycle cost (LCC) of a structure includes the totality of all the cost incurred in its life time (cradle-to-grave). This encompasses initial costs, including costs of design and construction; operation (utilities) cost; periodic maintenance (including repair); and eventual dismantling or demolition. LCC can be estimated based on Single Present Worth (SPW) as given in Equation 1 [39]. The equation gives the life cycle cost $\left(C_{\text {Lifecycle }}\right)$ based on SPW which discounts future costs and inflation based on the discounting factor $\left(\frac{1}{(1+i)^{y_{n}}}\right)$, where, $i$ is the discount rate and $y_{n}$ stands for the time in period of years associated with the different cost components 1 (Maintenance) to 6 (Dismantling).

$$
\begin{gathered}
C_{\text {Lifecycle }}=C_{\text {Initial }}+\sum \frac{1}{(1+i)^{y_{n 1}}} C_{\text {Maintenance }}+\sum \frac{1}{(1+i)^{y_{n 2}}} C_{\text {Inspection }}+\sum \frac{1}{(1+i)^{y_{n 3}}} C_{\text {Repair }}+ \\
\sum \frac{1}{(1+i)^{y_{n 4}}} C_{\text {Operating }}+\sum \frac{1}{(1+i)^{y_{n 5}}} C_{\text {Failure }}+\sum \frac{1}{(1+i)^{y_{n 6}}} C_{\text {Dismantling }}
\end{gathered}
$$

In reviewing the numerous conceptions on carbon footprint, Wiedmann and Minx [40] defined the term as a measure of the exclusive total amount of carbon dioxide emissions that is directly and indirectly caused by an activity or is accumulated over the life stages of a product. Carbon dioxide $\left(\mathrm{CO}_{2}\right)$ is the dominant gas release by human activities that contribute to global warming. As such it has been use as main substance of reference in the reduction of green house gas emissions [41]. On the other hand, ecological footprint concept was developed by Mathis Wackernagel et al in the early 1990's. Wackernagel et al [42] expressed that ecological footprint measures how much life-supporting natural capital, expressed in biologically productive area, is necessary to meet the resource demand and waste absorption requirements of a given population with links to demographic trends, economic expansions, changes in resource efficiency and economic prosperity. On the aspect of human settlements and infrastructure, ecological footprint (EF) assumes that artefacts occupy agriculturally fertile lands hence the productivity of cropland is used as the basis for expressing the ecological footprint in global hectares (gha) of a built-up area (A), as given in Equation (2). The equivalence factor (EqF) is the crop yield attainable in an area with an assumed level of input (water or fertilizer). The bio-capacity of different regions or countries can be obtained by scaling associated EF with a Yield Factor (YF), which gives the relative productivity measure of a given country with the global average of the same bioproductive area.

$$
E F_{\text {buit-up }}(g h a)=A_{\text {built-up }}(h a) \times E q F_{\text {built }-u p}(g h a / h a)
$$

On a more detailed level, the indicator parameters for sustainability are numerous and vary across countries and assessment tools. Table 1 lists the main assessment criteria featuring across assessment tools associated with selected countries. The common parameters include energy, ecology, indoor environmental quality, innovation, land use, pollution, transport and water. These parameters which can be broken down into varying sub-criteria are also considered on different basis and weighting ratios [43]. It is perhaps only energy related to the production of materials, ecology and land use that could have some direct reflection in structural sustainability considerations. Carbon emission is calculated as a function of embodied energy; hence carbon footprint and ecological footprint measures have been used to account for the environmental aspect in the proposed framework. Also, ecological footprint captures aspects of the use of natural resources such as land. The relative proportion of contribution these measures make to the overall building sustainability has been deduced to be about $26 \%$ based on the BREEAM rating system [44]. This excludes the economic aspect of sustainability. BREEAM ratings utilize weighting factors in computing overall scores and it is yet to incorporate economic criteria [45]. The basis of the deduced 26\% is in estimating the relative percentage of aggregated weightings of BREEAM assessment sub-criteria reflecting aspects of carbon footprint and ecological footprint measures. As such, the option of a structural design solution assessed (by the prototype) to perform better than other alternatives will score a good proportion of the $26 \%$ contribution. This means that chosen option will have higher chances of achieving high overall BREAM rating provided the performance in the remaining $74 \%$. 
Table 1: Main criteria of assessment tools (Modified after [46])

\begin{tabular}{|c|c|c|c|c|c|}
\hline Assessment Criteria & $\begin{array}{l}\mathbf{U K} \\
\text { BREEAM }\end{array}$ & $\begin{array}{l}\text { Hong Kong } \\
\text { BEAM }\end{array}$ & $\begin{array}{l}\text { Australia } \\
\text { Green Star }\end{array}$ & $\begin{array}{l}\text { U.S. } \\
\text { LEED }\end{array}$ & Tally \\
\hline Energy & $\mathrm{x}$ & $\mathrm{x}$ & $\mathrm{x}$ & $\mathrm{x}$ & 4 \\
\hline $\mathrm{CO} 2$ & $\mathrm{x}$ & & & & 1 \\
\hline Ecology & $\mathrm{x}$ & $\mathrm{x}$ & $\mathrm{x}$ & $\mathrm{x}$ & 4 \\
\hline Economy & & & & & 0 \\
\hline Health and wellbeing & $\mathrm{x}$ & $\mathrm{x}$ & $\mathrm{x}$ & & 3 \\
\hline Indoor env. quality & $\mathrm{x}$ & $\mathrm{x}$ & $\mathrm{x}$ & $\mathrm{x}$ & 4 \\
\hline Innovation & $\mathrm{x}$ & $\mathrm{x}$ & $\mathrm{x}$ & $\mathrm{x}$ & 4 \\
\hline Land use & $\mathrm{x}$ & $\mathrm{x}$ & $\mathrm{x}$ & $\mathrm{x}$ & 4 \\
\hline Management & $\mathrm{x}$ & $\mathrm{x}$ & $\mathrm{x}$ & & 3 \\
\hline Materials & $\mathrm{x}$ & $\mathrm{x}$ & $\mathrm{x}$ & & \\
\hline Pollution & $\mathrm{x}$ & $\mathrm{x}$ & $\mathrm{x}$ & $\mathrm{x}$ & 4 \\
\hline Renewable Technologies & $\mathrm{x}$ & & $\mathrm{x}$ & $\mathrm{x}$ & 3 \\
\hline Transport & $\mathrm{x}$ & $\mathrm{x}$ & $\mathrm{x}$ & $\mathrm{x}$ & 4 \\
\hline Waste & $\mathrm{x}$ & $\mathrm{x}$ & & & 2 \\
\hline Water & $\mathrm{x}$ & $\mathrm{x}$ & $\mathrm{x}$ & $\mathrm{x}$ & 4 \\
\hline
\end{tabular}

\subsection{Modelling requirements}

One essential aspect of the implementation of the sustainability modelling prototype is the identification of high level requirements capturing the needs of the industry and users. For sustainability appraisal, a clear description of the components of the indicators is very important. These indicators should reflect the key aspects of sustainability and it should also be possible to compare options of objects or systems being assessed. To keep pace with contemporary and future IT innovations, integration of such prototype with BIM or existing product models is very essential. The implementation requirements have been identified to include being generic, formal, flexible, scalable and easy-to-use as given in Figure 2. The prototype should consider generic building elements, using structured computer representation of information flexible enough and scalable to accommodate manipulation of varied use conditions within the scope of implementation 


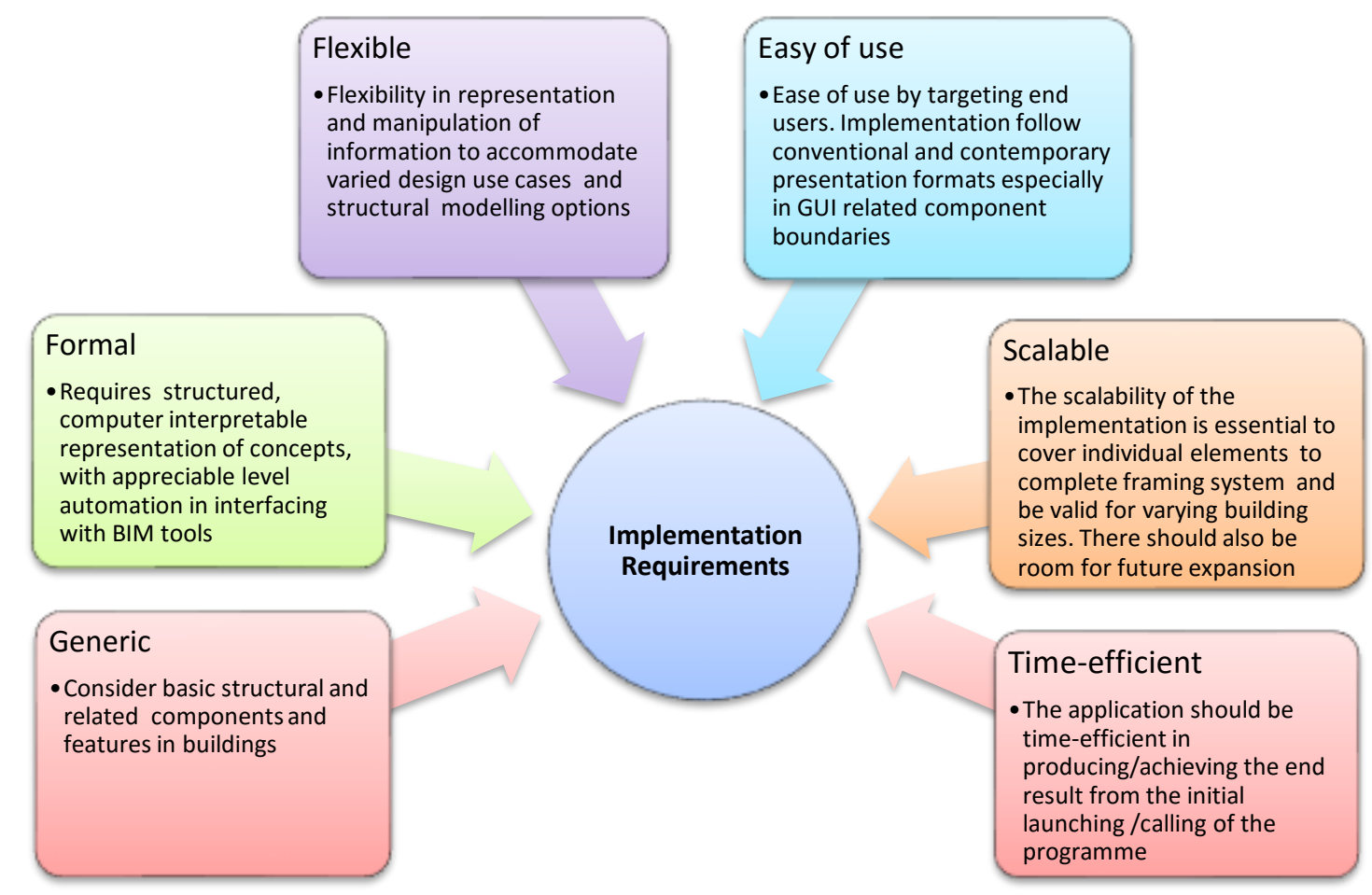

Figure 2: Implementation Requirements

\subsection{Feature representation and modelling framework}

The feature representation in this research is described based on the four activities; Feature Type, Feature Library, Feature Modeling and Feature Modification discussed in Section 2.2.

\section{- Feature Type definition}

Feature type may be generic or specific. It is generic when it forms the building's core model and is among the formalized common concepts in the AEC industry; and on the other hand specific, if it is not part of the common AEC domains [31]. Since a prototype implementation is intended in this research, the features selected are largely of the generic type. They include column, beam, floor, roof and cladding systems. These features could also be termed as "component features" [23, 47]. These features are extracted by means of their definition type in the form of domain name, family instances, and identification codes.

\section{- Feature Library}

Feature types are classified into sections contained in the Feature Library which is a function of a particular domain area in the AEC industry. The Feature library in this research is implemented through Microsoft Structures Query Language (SQL) database management system within the .NET Frameworks and contains various instances of the feature types. Figure 3 shows the UML schema diagram of the Feature Library for the column Feature Type. "Column" is a feature type that belongs to a section within the AllSectionData, UC254x254x73 is a type of column representing one of the examples of a feature instance and has material properties, cost, boundary conditions (end connection) etc. AllSectionData is housed in the database named SteelSectionData which serves as the Feature Library in the implementation. 


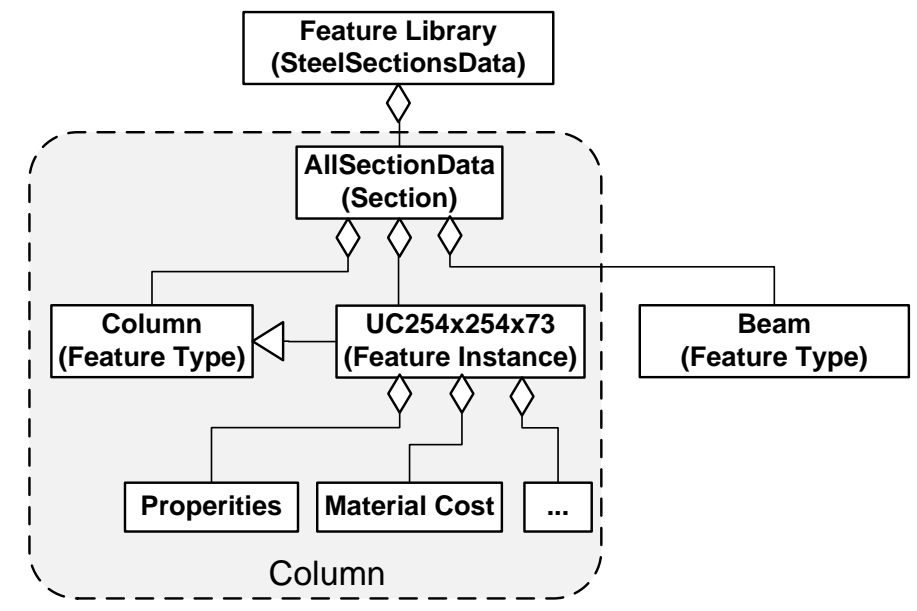

Figure 3: Column mappings in the Feature database

\section{- Feature modelling}

This refers to the instantiation of a selected feature type that suits the type of information to be modeled [31, 32]. This aspect is executed in the $\mathrm{C \#}$ object oriented environment through interfacing with BIM enabled tools such as Revit Structures ${ }^{\mathrm{TM}}$. It entails recognizing and extracting the considered feature types from a particular design model (BIM). This forms the basis for comparing and abstracting corresponding cost and life cycle information from the feature library for appropriate collation and onward sustainability analysis.

\section{- Feature modification}

The modification of features that could take place during the operation of the prototype presented in this paper is largely related to the issues concerning the chosen sustainability indicators. However, the intention for feature modification include the possibility of altering the values of various attributes of features, deleting or introducing new relationships between features which trigger features to respond in some particular manner [31]. Some of the modifications associated with feature modeling process used in the structural sustainability modeling include: altering of cladding area; specification of discount rates and estimated maintenance costs; indication of associated lifecycle boundaries for the sustainability analysis etc.

From the feature-based modelling perspective, the modelling framework (Figure 4) consists of the conceptual model, the feature extraction module and the feature modelling aspect. The conceptual model is essentially a building product model in a BIM enable tool which is capable of allowing the extraction of feature components for sustainability analysis. The proposed sustainability modelling framework reflects the economic and environmental aspects of the sustainability of steel framed buildings. It uses life LCC techniques to account for the economic sustainability and a combination of carbon footprint and ecological footprint measures to account for environmental sustainability. The framework has been implemented in a prototype system which is dependent on significant amount of data from secondary sources. This encompasses methods for construction and fabrication of materials, associated costs, life cycle information; combined with the application methodologies of the selected sustainability indicators. The implementation work uses the $\mathrm{C \#}$ object oriented programming (OOP) application within the .NET Framework environment. The output of the prototype is fine-tuned by sensitivity and risk analysis to increase the reliability of the estimations of sustainability indicators. 


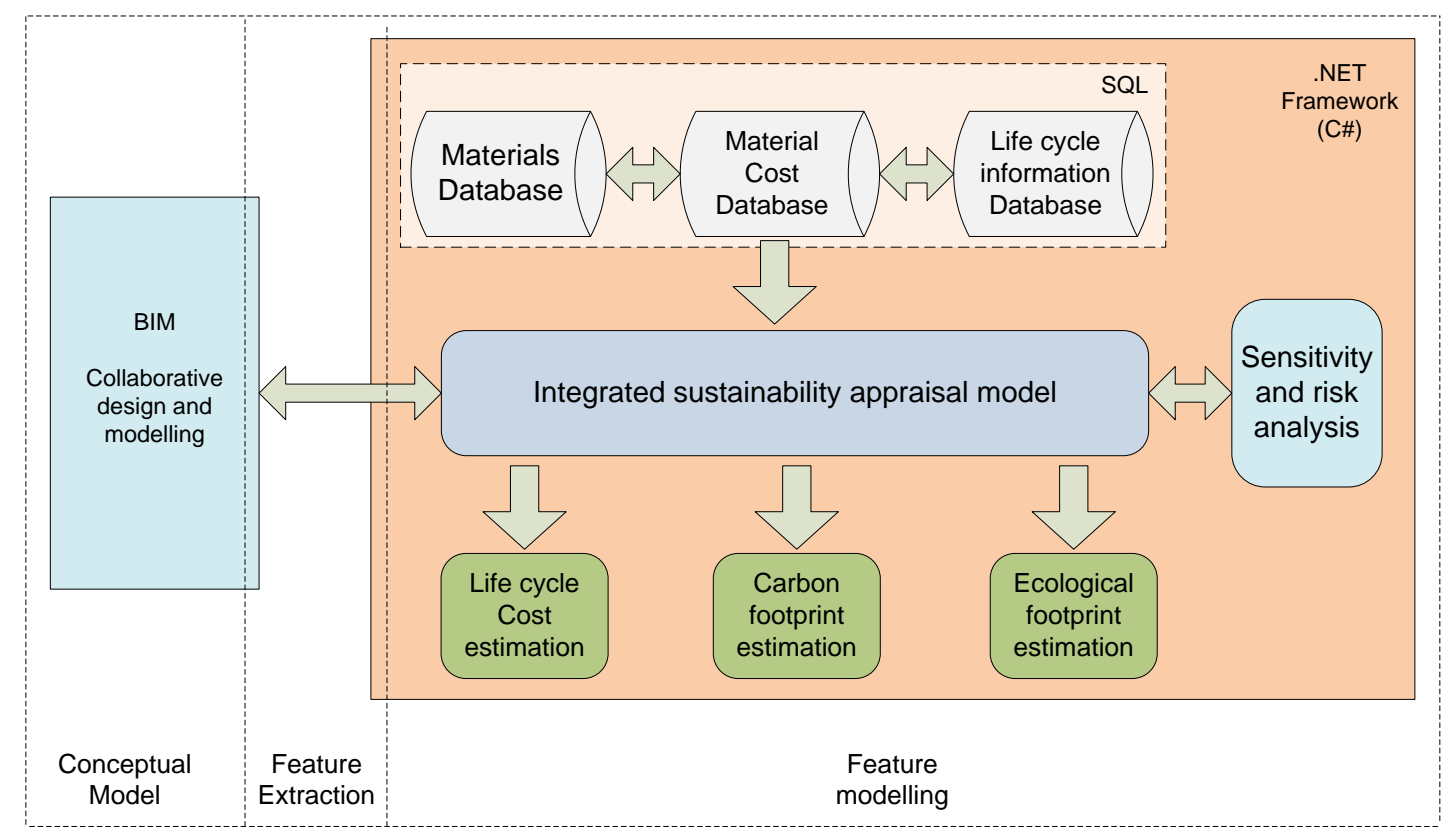

Figure 4: Proposed sustainability modelling framework

\subsection{Framework implementation}

This work combines the area of sustainability and information technology which are individually vast. It is therefore important to specify the scope of this research with respect to the key aspects relating to: the building life cycle stage, sustainability dimensions, structural framing options, detail of building elements, modelling platform and the implementation scope.

- Building life cycle stages

The building life cycle primarily consists of planning and design, construction, operation and endof-life stages. A holistic approach requires combining all these stages in sustainability analysis.

- Sustainability dimensions

It is possible to carry out separate assessments on each of economic, economic and social dimensions, depending on scope (BS EN 15643-1, 2010). In this research, it is only the economic and environmental dimensions that have been considered.

- $\quad$ Structural framing options

The structural framing option in this research is structural steel. Other available options include insitu concrete and precast concrete. Structural steel was chosen in order to provide a focus for the research; however, there are possibilities to extend the implementation to account for other framing options.

- Detail of building elements considered

There are a vast number of elements that comprise a building. The degrees of contribution of these elements to the overall building sustainability vary. From a structural point of view, key elements in the structural systems that are accessible for maintenance, re-use and recycling are the most important. This research therefore considered elements found in the superstructure of typical structural framing systems. These elements include columns, beams, structural floor systems, and cladding and roof systems.

- The implementation scope

The scope of implementation is limited to developing the prototype as a proof of concept demonstrating the sustainability modelling framework. The possibility of extending the prototype to widen its scope has been considered in the implementation. 


\subsubsection{Implementation of prototype}

The prototype implementation is in two parts and employs the feature modeling approach. The first aspect involves developing a sustainability assessment model of design features using object-based modeling techniques in C\# .NET environment. This aspect was initially implemented independent of the BIM environment where conceptual design activity is performed. The second aspect entails integrating the sustainability assessment model with conceptual building design iterations in the building information modeling process. This second aspect is developed based on the processes associated with feature extraction activity. The fundamental activities making up these two aspects of the prototype implementation include use-case elicitation, development of programming algorithms and the process of representing features as objects in the programming environment.

The elicitation of a use-case (Figure 5) has been used to guide the programming direction. The sources of information for developing the use-case are through domain knowledge analysis [48, 49], related literatures $[50,51]$ on the subject and refinement through regression testing of the framework. The use-case portrays how the actor, a structural engineer in this case, interacts with the proposed system to produce appraisal results of alternative design solutions. It entails the structural engineer registering the project information and design details of the project, and feeding in required information related to cost components, impact of elements and time. Table 2 gives details of the interactions instantiated by the various use-case components. General information for the project is captured by the first two components, 1 and 2 as the user commences the assessment process. Components 3-7 and 7-9 are parallel paths to obtain the economic and the environmental indicator measures. This operation is performed for the respective alternative design options, compared and analysed by the structural engineer to round-up the process as depicted by case 10 . The economic and environmental appraisal is done through appropriate indexing and weighting method from generated results on the corresponding indicators. The onus therefore rests on the engineer on how to combine the indicators to make a judgement vis-à-vis other factors such as prestige, future potential changes and project longevity. Sequence of actions characterizing components of the use-case diagram is further captured by algorithms guiding the implementation of the sustainability appraisal framework.

Table 2: Use-case component interactions

\begin{tabular}{|c|c|c|c|}
\hline S/No & $\begin{array}{l}\text { Use-case } \\
\text { scenario }\end{array}$ & $\begin{array}{l}\text { Instances of } \\
\text { Actor's action }\end{array}$ & $\begin{array}{l}\text { Functions of System } \\
\text { and responses }\end{array}$ \\
\hline 1 & $\begin{array}{l}\text { Enter Project } \\
\text { Information }\end{array}$ & Title, location & Store information \\
\hline 2 & $\begin{array}{l}\text { Enter details of design } \\
\text { result }\end{array}$ & $\begin{array}{l}\text { Design life, Material type, } \\
\text { building dimensions }\end{array}$ & $\begin{array}{l}\text { Initialize extracted building } \\
\text { features, store supplied information }\end{array}$ \\
\hline 3 & Estimate Initial Cost & $\begin{array}{l}\text { Inspect components and material } \\
\text { information, Instruct system }\end{array}$ & $\begin{array}{l}\text { Call stored information, Calculate } \\
\text { quantities and initial cost }\end{array}$ \\
\hline 4 & $\begin{array}{l}\text { Identify recurrent \& } \\
\text { end-of-life costs }\end{array}$ & $\begin{array}{l}\text { Determine recurrent cost, supply } \\
\text { frequencies and discount rates }\end{array}$ & Store information for initialisation \\
\hline 5 & $\begin{array}{l}\text { Compute \& optimize life } \\
\text { cycle costs }\end{array}$ & Instruct system & $\begin{array}{l}\text { Computes lifecycle cost from initial } \\
\text { cost and other determined costs }\end{array}$ \\
\hline 6 & Perform Risk Analysis & $\begin{array}{l}\text { Select components, supply } \\
\text { possible cost variations }\end{array}$ & Simulate cases and display results \\
\hline 7 & Assess life cycle impacts & $\begin{array}{l}\text { Decide aspects of environments } \\
\text { impact to assess and proceed }\end{array}$ & $\begin{array}{l}\text { Instantiate life cycle information of } \\
\text { materials from stored data } \\
\text { (database) }\end{array}$ \\
\hline 8 & $\begin{array}{l}\text { Generate Carbon } \\
\text { Footprint }\end{array}$ & $\begin{array}{l}\text { Specify life cycle boundary, } \\
\text { material recovery status }\end{array}$ & $\begin{array}{l}\text { Generate calculations for carbon } \\
\text { footprint measure }\end{array}$ \\
\hline 9 & $\begin{array}{l}\text { Generate Ecological } \\
\text { Footprint }\end{array}$ & $\begin{array}{l}\text { Confirm or specify building area, } \\
\text { Ecological footprint factors }\end{array}$ & $\begin{array}{l}\text { Calculate structure's ecological } \\
\text { footprint measure }\end{array}$ \\
\hline 10 & $\begin{array}{l}\text { Appraise sustainability } \\
\text { of design options }\end{array}$ & $\begin{array}{l}\text { Specify indicators combination } \\
\text { weighting, Instruct system, inspect } \\
\text { result, make decision }\end{array}$ & $\begin{array}{l}\text { Compare options sustainability } \\
\text { measures, generate visual chart of } \\
\text { option performances. }\end{array}$ \\
\hline
\end{tabular}




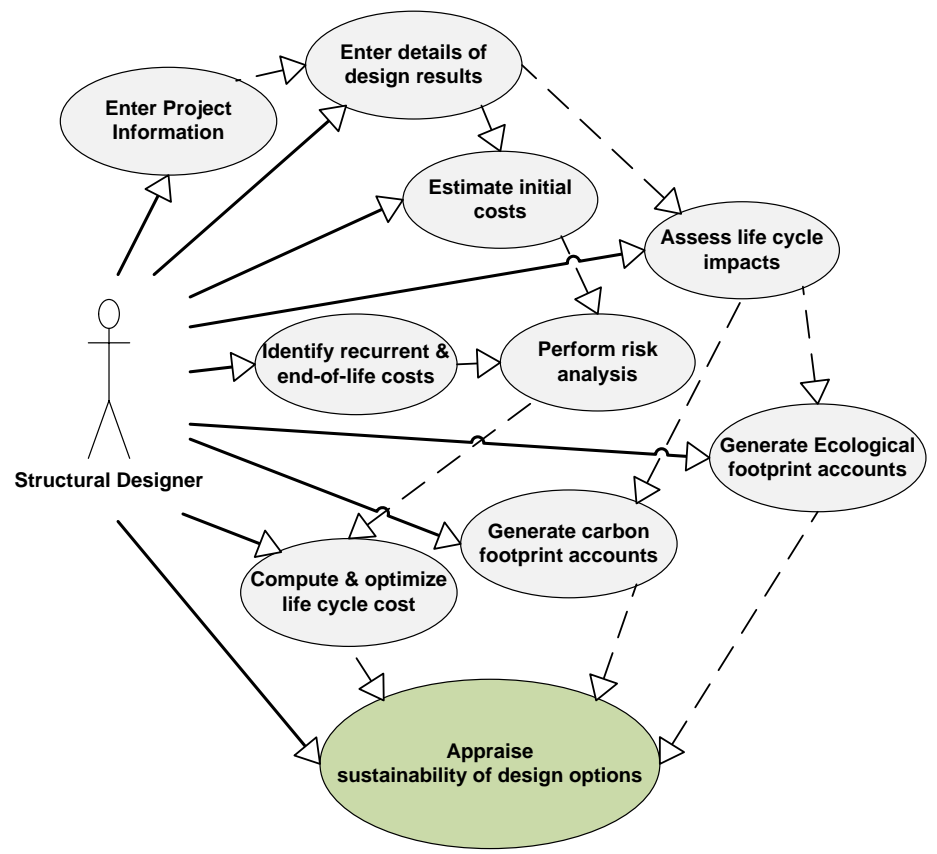

Figure 5: Use-case

The algorithm for the implementation of the prototype is shown in Figure 6. It is broken down into 8 sections which include the project registration aspect, initial cost estimation part, the economic aspect represented by lifecycle cost estimation and the environmental aspect comprised of carbon footprint and ecological footprint measures. The remaining four sections relate to exploring what-if scenarios application, comparing design option on multiple criteria basis, and conducting risk and sensitivity analysis. The algorithm for risk and sensitivity is represented by ' $R$ ' in Figure 6 and further detailed in Figure 7.

The overall flow in the algorithm entails calling up the decision-support programme from a BIMenabled programme while carrying out structural modelling activities. The next requirement in the sequence of events is to provide requisite identification for the project by registering project information and assigning design option IDs. The sequence of events then flows through a decision making process on three alternative modes (Manual entry of building elements, Assess building from IFC model or Assess building from native BIM format) of operation to extract building features (columns, beams, connection details, floor etc.) for onward sustainability assessment. The alternative operation modes are housed in the Project Registration section to allow the designer select one preferred mode, out of the three pathway options, for progressing through the system immediately after providing the general project information. It is envisaged that the system will provide designers with these three independent options of selecting manual entry of building elements to supply elements of the building, extracting elements from an IFC model for analysis or selection of native BIM option such as a Revit project model for the extraction of elements. 


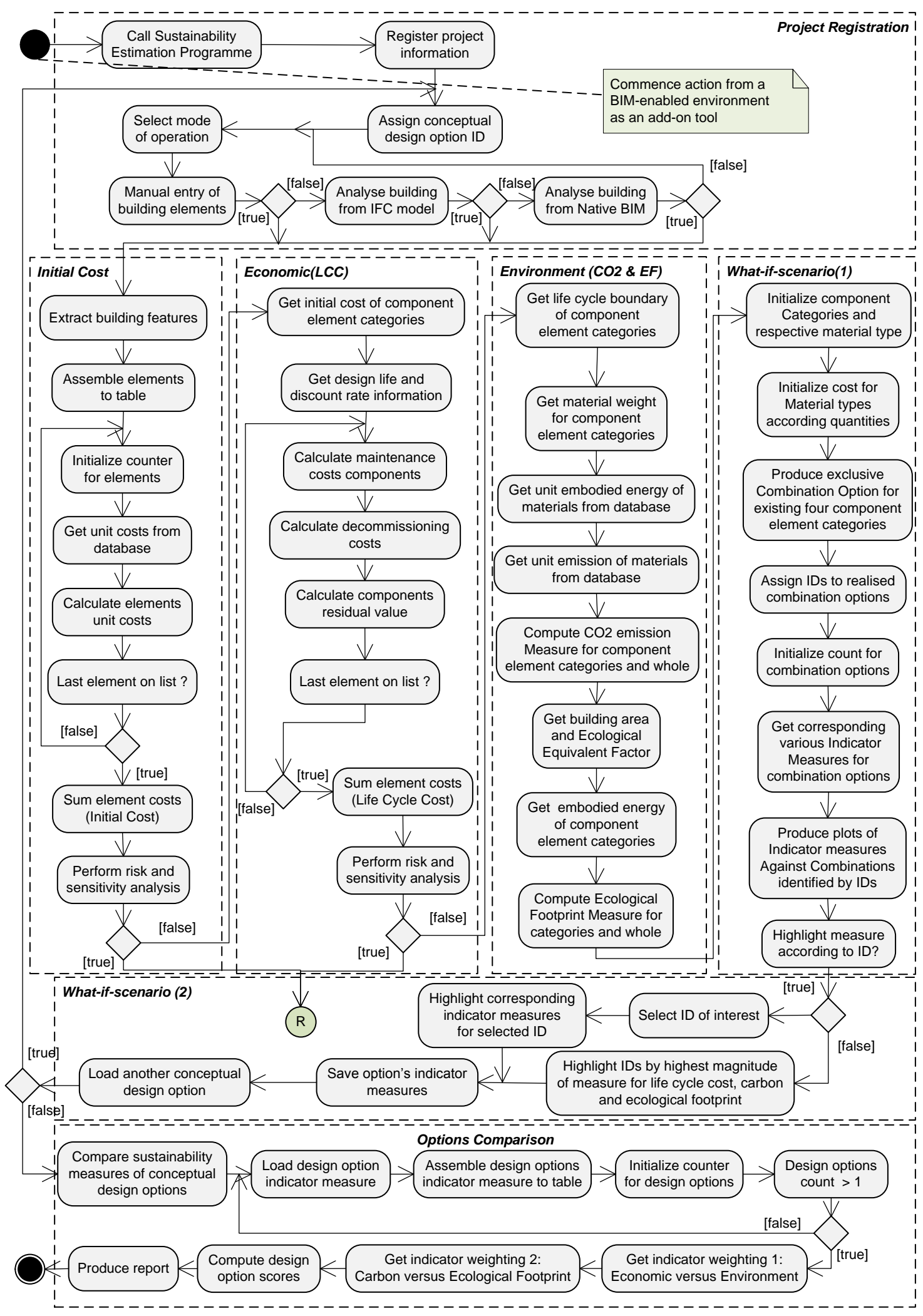

Figure 6: Sustainability decision-support algorithm 
Once the decision on mode of assessment is made and the relevant features are extracted, the sequence of assessment steps through the estimation of Initial Cost, Life Cycle Cost, Carbon Footprint, and Ecological Footprint. Sustainability research has shown appreciable contrasts regarding data and principle for calculating indicator measures used for assessment purposes. The method proposed in this research is probably not free of such critiques as it is based on the use of secondary data. Given that such information change with time, either from refinement or addition of new data, the system considers the need to update secondary data. However, key to the system is modelling sustainability information and combining assessment criteria to inform structural conceptual design activity. The algorithm also includes room for the designer to explore the performance of various combinations of materials in what-if scenario situations. After saving the estimated measures of the indicators, the process can be repeated for more design options and eventually compared on multi-criteria basis of the three sustainability indicators. The comparison then brings out the most favourable design based on the relative performance of the design options. The last event in the sequence before termination is to produce necessary reports for the assessment

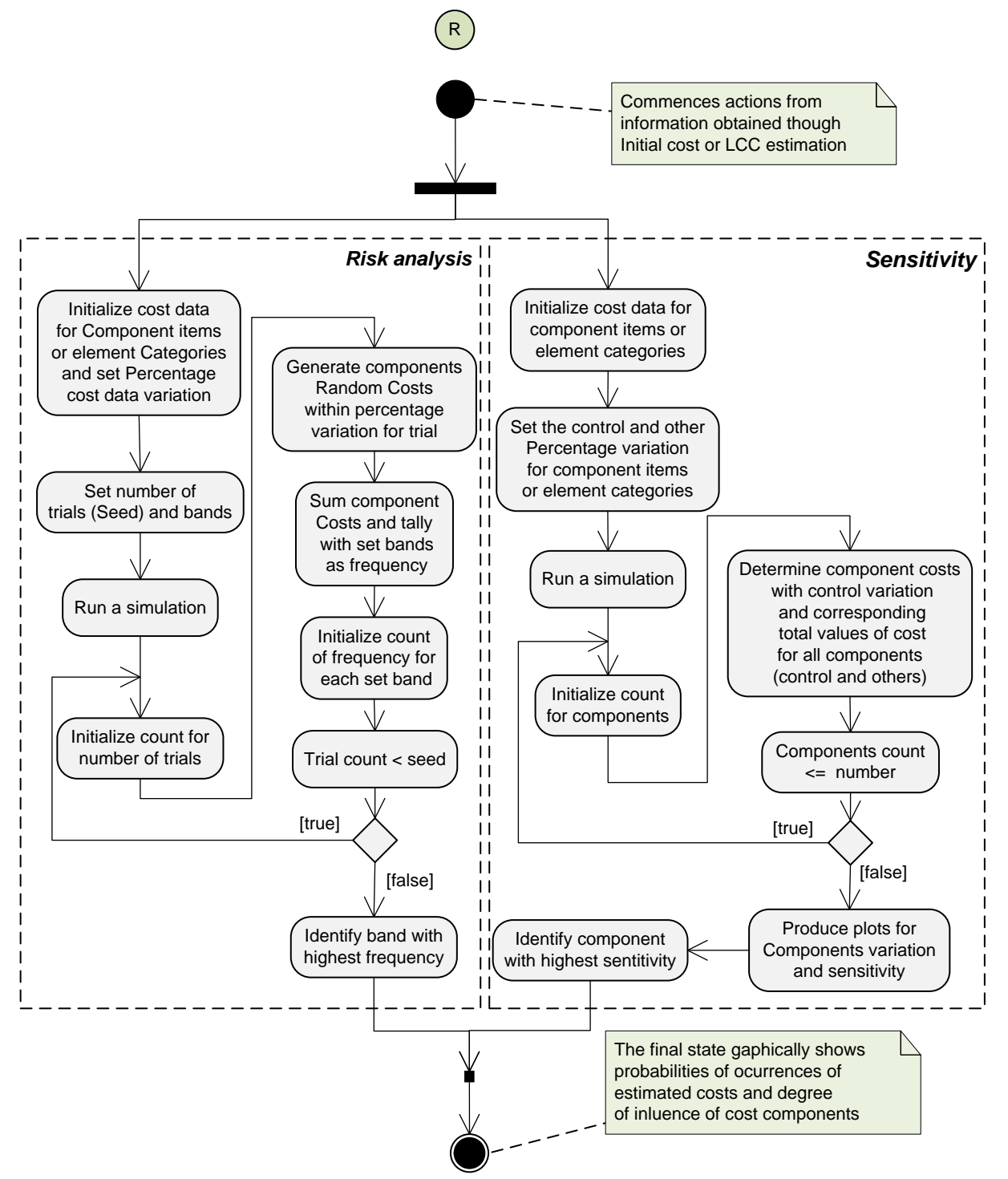

Figure 7: Risk and sensitivity application algorithm

In the Initial Cost Estimation part, extracted features and their corresponding properties and quantities are grouped according to component categories such as frame (beams and columns), floor, roof and 
cladding. This will allow easy interaction with a database management system to draw up corresponding cost information. It is important that information prone to changes remain in a database separate from actual programming environment because of the need to update records periodically. After the cost of all individual elements has been calculated, the sequence moves on to sum the costs according to component categories and for the overall initial cost. At this stage it is possible to perform an early check of risks of the estimation and also identify the most sensitive cost component or component element category. More detailed risk and sensitivity check can be done when the life cycle cost measure has been estimated. The LCC aspect commences with the initialization of the initial cost of component element categories (Frame, Floor, Roof and Cladding). It flows through getting information such as design life and discount rates needed for the conversion of costs to present day money value. The algorithm then steps through the estimation of various cost components such as maintenance, decommissioning and residual value to aggregate the life cycle cost of components categories. This is used to obtain the overall life cycle cost. For the environmental assessment aspect, the designer is required to supply options for end-of-life boundary conditions. The underlying processes rely on the accompanying database management system to supply information on emission factors, ecology factors and embodied energy of materials. These are combined with abstracted quantities to calculate the carbon footprint and ecological footprint measures of the design options.

The purpose of exploring what-if scenarios is to make provision to check and compare the performance of combination options for other material types featuring in the prototype. This allows the designer to get abreast with alternative materials to consider as substitute if the need arises. The algorithm assumes that the three indicator measure for the combination option abstracted from the building model form part of the options for consideration. It groups existing material types by name, quantities and the estimation of their respective costs according to component element categories. These categories are exclusively combined and assigned option identification numbers. Table 3 gives the list of categories of building materials types and the number of available options for combination. There are a total of 12 material types which can be exclusively combined in 48 possible ways. The system could be expanded to include more material types in the component categories.

Table 3: Building components material type combination

\begin{tabular}{lll}
\hline Component & Material Options & Combinations \\
\hline Framing & steel & 1 \\
Floor & In-situ concrete, Precast, Metal Decking & 3 \\
Roof & Clay tiles, Concrete Tiles, Metal Sheet, Slate & 4 \\
Cladding & Aluminium, Steel, Fibre Cement, Plasterboard on Metal & 4 \\
\hline
\end{tabular}

In the case of considering another existing design option, the designer will be required to load the corresponding information for that option. Options are compared based on the principle of multiple criteria decision method. It essentially combines criteria with different units by apportioning performance weightings to calculate relative score of options. Weightings are provided at two levels. The first level is the economic and environmental contributions. How the carbon and ecological footprint are to be combined for the environmental aspect is specified at the second level. The system computes relative scores for the various design options being compared based on the specified weightings and identifies best performance option by the magnitude of their scores. It employs the Multiple Attribute Decision Making (MADM) which is a more suitable option of multi-criteria decision analysis for the requisite task in this work. This is because the method has the advantage of allowing the comparison of attributes with different units of measurement by the use of weighting factors [52]. Also the number of conceptual design options to be compared will be finite and decisions will be based on information that is not yet finalized or complete [53]. In addition, the method allows trade-offs among attributes as it is envisaged that no single alternative will exhibit preferred value for all attributes [54]. The method also has the advantage of allowing the comparison of attributes with different units of measurement by the use of weighting factors. 
Thus the desirability score for each option is given by Equation 3 [54]. It gives the summation of the contribution of each attribute with respect to the cardinal numerical score for each alternative conceptual design solution. The most favourable option will be the solution with the highest desirability score.

$$
D_{j}=\sum_{i=1}^{n} w_{i} x_{i j}
$$

Where, $\quad D_{j}=$ Desirability score for a particular alternative

$n=$ Number of attributes associated with the options

$w_{i}=$ Weight (normalised) of attribute or criteria

$x_{i j}=$ Score of the alternative on the particular criteria

Risk analysis can be performed for the initial cost and the life cycle cost of the structure as illustrated in Figure 6 and Figure 7. A description of the actions of the user and corresponding function of the system is detailed in Table 4. The illustration in Figure 7 starts by the initialization of the cost information for cost component items (Initial Cost, Maintenance, Decommissioning and Residual Value) or the component element categories (Frame, Floor, Roof and Cladding). The next action is for the designer to specify the number of trials or seed and to set the number of bands for apportioning frequency of occurrence. The range of the sets of bands fluctuates around the various initialized cost information of components in the previous step. After the number of trial runs attains the seed on performing a simulation, the band with the highest frequency is identified as the most probable outcome from the analysis. The knowledge of this value can be used as a basis for re-assessing the desirability score of design options and in making final decisions. The sensitivity aspect also considers cost component items or component element categories. The first action is the initialization of the cost data and then specifying the control percentage variations for components. The step to run a simulation triggers the system to alternate the control variation with the cost of the various components to generate sets of pairs of cost data which can be plotted to graphically identify the most sensitive components

Table 4: Description of risk analysis component actions

\begin{tabular}{|c|c|c|c|}
\hline S/No & Event & User actions & System function \\
\hline 1 & Initialize cost data & $\begin{array}{l}\text { Activate command for risk } \\
\text { analysis }\end{array}$ & $\begin{array}{l}\text { Retrieve components information } \\
\text { and related calculated cost data }\end{array}$ \\
\hline 2 & $\begin{array}{l}\text { Set number of trials and } \\
\text { bands }\end{array}$ & $\begin{array}{l}\text { Specify number of runs, bands } \\
\text { and component variation }\end{array}$ & $\begin{array}{l}\text { Store data and initialize for } \\
\text { simulation }\end{array}$ \\
\hline 3 & Run a simulation & $\begin{array}{l}\text { Initiate command to run } \\
\text { simulation }\end{array}$ & Commence simulation process \\
\hline 4 & $\begin{array}{l}\text { Initialize counts for } \\
\text { trials }\end{array}$ & & Determine counts \\
\hline 5 & $\begin{array}{l}\text { Generate components } \\
\text { random costs }\end{array}$ & & $\begin{array}{l}\text { Compute random costs for } \\
\text { components cost items or elements }\end{array}$ \\
\hline 6 & $\begin{array}{l}\text { Sum components costs } \\
\text { and tally frequency }\end{array}$ & & $\begin{array}{l}\text { Aggregate frequencies } \\
\text { corresponding to summed } \\
\text { components costs }\end{array}$ \\
\hline 7 & $\begin{array}{l}\text { Initialize count for band } \\
\text { frequency }\end{array}$ & & $\begin{array}{l}\text { Generate counts of frequency for } \\
\text { each set band }\end{array}$ \\
\hline 8 & $\begin{array}{l}\text { Trial count less than } \\
\text { seed }\end{array}$ & & $\begin{array}{l}\text { Check count against seed to repeat } \\
\text { process if 'less than', else proceed }\end{array}$ \\
\hline 9 & $\begin{array}{l}\text { Identify highest } \\
\text { frequency }\end{array}$ & $\begin{array}{l}\text { Check output and note } \\
\text { components impacts on } \\
\text { aggregated costs }\end{array}$ & $\begin{array}{l}\text { Produce visual results of } \\
\text { components influence based on } \\
\text { occurrence frequency }\end{array}$ \\
\hline
\end{tabular}


Two main aspects of risk analysis entail quantifying risk factors and determining their influence on aggregated costs. The aspect of risk analysis in this work dwells on identifying the influence categories of cost component items and elements, as factors, have on the measure of aggregated cost. As such, the aspect of risk reflected in the analysis is the variation in the costs of components. This will help to keep designers informed on the effects of components variations on costs, the possible impact on the project and room to explore other combinations of component materials. Variations of actual cost from estimated values could result from number issues such as mistakes in design calculation, inaccurate estimations of material quantities, faulty design assumption etc. The factors and their respective influences on the aggregated costs have been represented in probability mass functions/ frequency distributions in accordance with the Monte Carlo Method. The Monte Carlo Method is a widely employed statistical technique in risk analysis [55-58].

For this research, normal distribution is assumed for the variables which involve costs associated with building material types used for framing, floor, roof and cladding termed as the component element categories. The normal distribution is suitable for this analysis because once the sustainability measure such as the life cycle cost is estimated; it is possible to obtain the minimum and maximum variation from the estimate by applying a predetermined factor for the sample range. This range then provides the known variable for generating the normal distribution curve. Thus, random numbers can be generated, for example, around the estimated life cycle cost of the identified best performed option. These generated random values of life cycle cost make up the sample for which the sample mean can be calculated. The application of computer programming technology makes generation of such random values, in terms of scale and number of trials, possible in successive simulation runs. Trial runs can be increased to reduce the degree of uncertainty in the estimated sample mean. In addition, the probability of occurrence of the sample mean can be obtained from a corresponding cumulative density function curve.

Another vital aspect of prototype implementation requires the mapping of frameworks, architectures, algorithms and entities to objects and rules for initialization and instantiation as programmable codes. Figure 8 shows examples of objects featured in the prototype and their respective simplified decomposition. The objects in a Building include Component which is decomposed into Frame, Floor, Roof Cladding, Cost and Indicator. Although Cost and Indicator are associated with other components, they have been presented at the second decomposition level to show how their different decompositions have been captured. For example, Carbon Footprint is parent to carbon footprint of Frame, Floor, Roof and Cladding. The Frame object may be decomposed into Steel and Concrete which is not within the scope of this implementation. Floor object has child objects as types of floors such as in-situ concrete, precast - on steel beams, and metal decking. Also, Section and Connection objects give rise to childobjects universal beam (UB) and universal column (UC) as section types, characterized by Plate, End Plate, Haunch etc. as associated connections. Similar reasoning have been observed in representing other main-objects working together and governed by object-rules and relationships. These objects have been correspondingly represented in a database system to store object properties and information that may need to be updated in the future. 


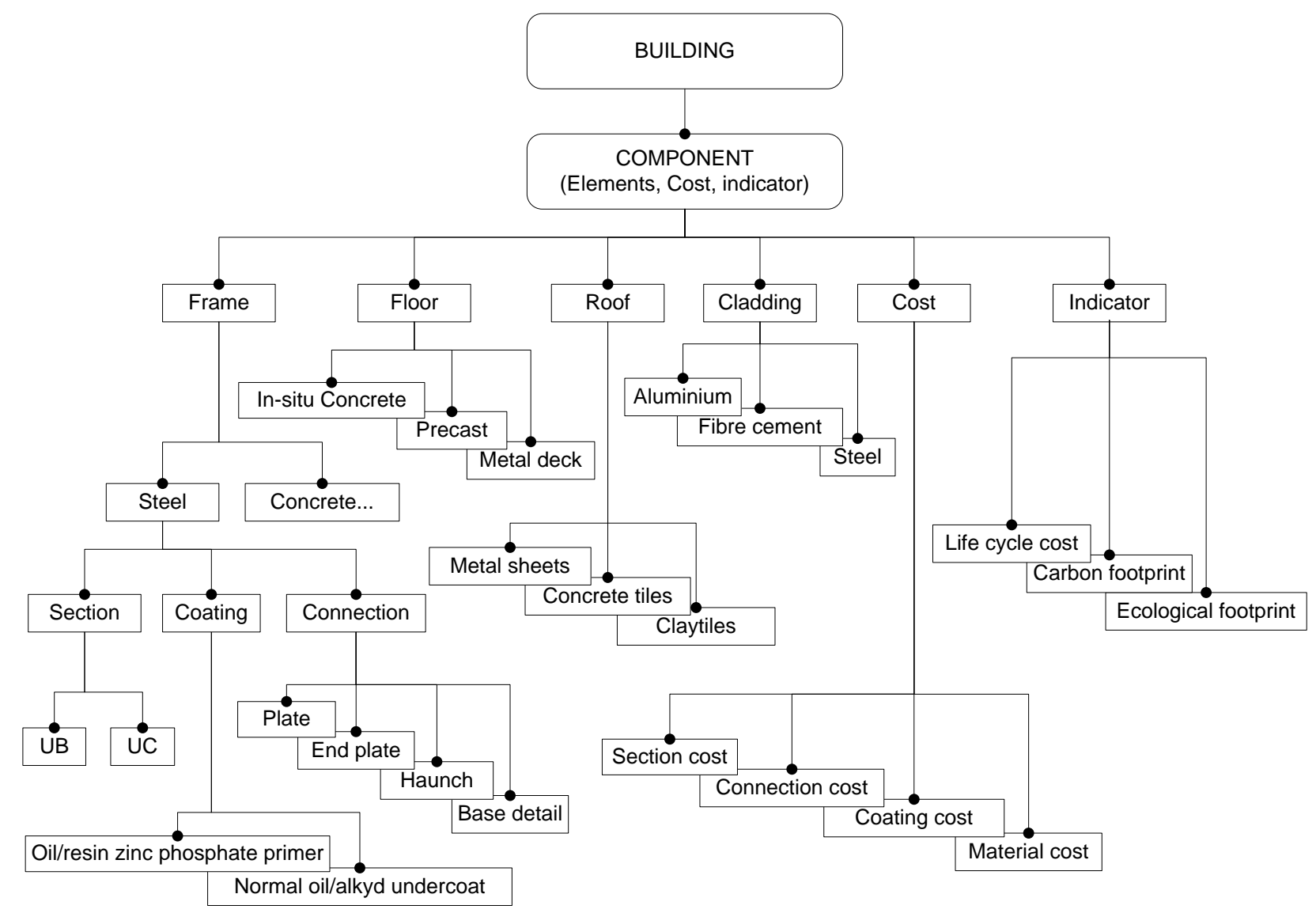

Figure 8: Object decomposition

The class diagram that ensued from the implementation process is depicted in Figure 9. It consists of ProjectDesignOption, ElementCollection, Element classes, and the sustainability indicator classes (LifeCycleCosting, EcologicalFPMeasure and CarbonFPMeasure). The Element Class obtains its members when the user triggers feature extraction activity. Thus, structural feature types are recognized from the product model and interaction with the feature library (database) is instantiated to get appropriate data needed for estimating associated sustainability measures. The ElementCollection gathers this information for the sustainability indicator classes to synthesize and obtain the appropriate measures. These aspects constitute sequence of events and processes comprising the operation of the prototype. 


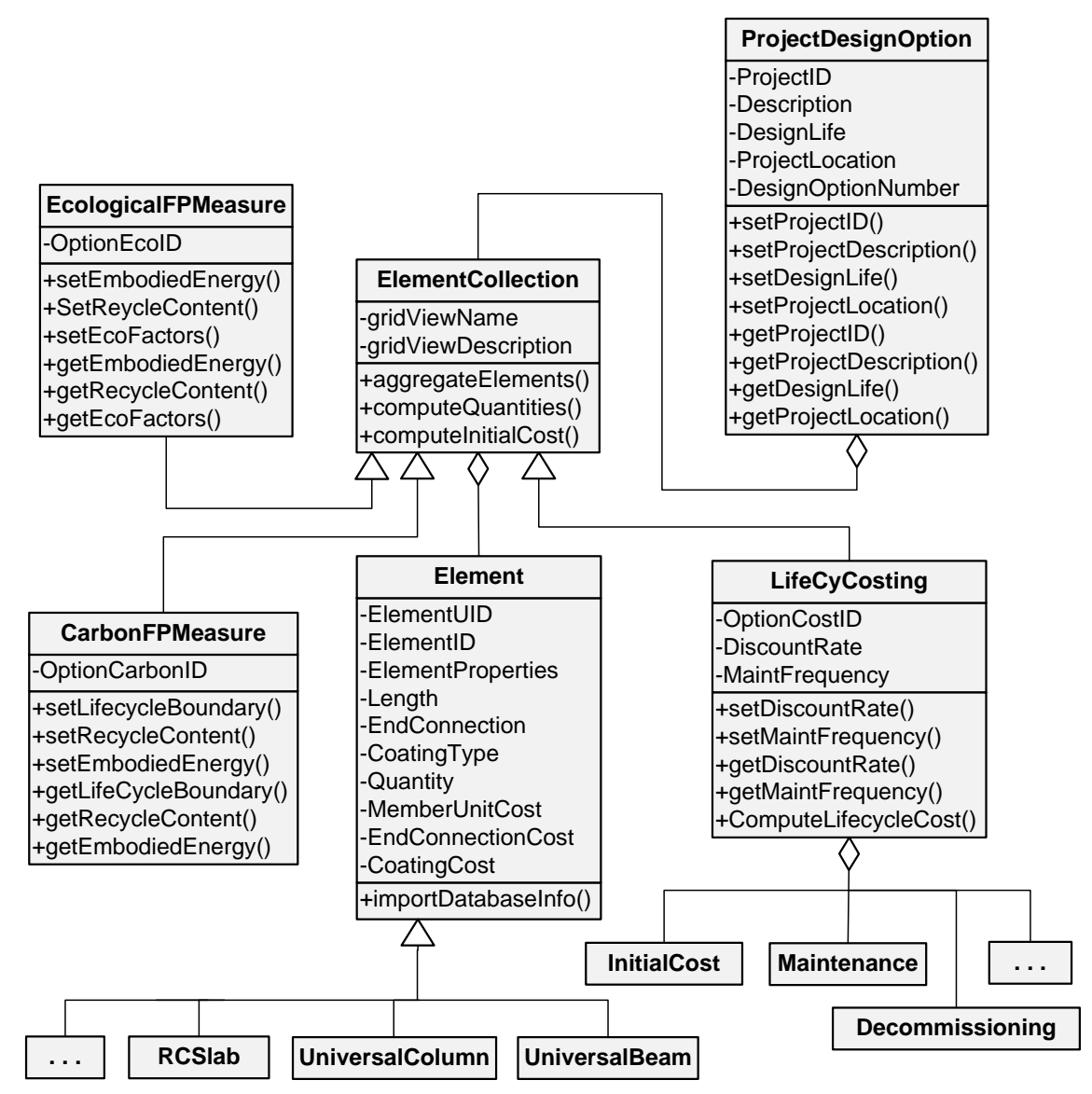

Figure 9: Implementation class diagram for the structural sustainability framework

The prototype is implemented in C\# object-oriented language of Visual Studio 2010. It takes advantage of integrated packages contained in the Microsoft Visual Studio .NET Framework and has been interfaced with Revit Structures 2011 to run as an add-in tool. The programme can be called by the designer during a building's structural modelling activity through the external link embedded in the Revit Structures. Figure 10 shows the implementation sequence diagram describing the flow of information in the prototype. The diagram has been simplified to show four major components; the Designer, User Interface, OperationMode and SustainabilityEstimator. The sequence of events conforms to the illustration given by the sustainability decision support algorithm given in Figure 6.

To further highlight the data exchange process between the designer and the prototype, Figure 11 shows a system sequence diagram [59] summarising the associated input and output information. It consists of the main objects; the designer and the system. The system is a simplified representation of the sustainability estimation prototype. An object for the building information model (BuildingModel) and two vital components (MaterialDatabase and RiskSensitivity) of the system have also been represented on the system side in order to show certain essential communication steps. As indicated in the figure, the appraisal is carried out in BIMenable software such as Revit Structures design environment. The designer is required to specify identifiers for alternative design solutions of the project and the mode of operation of the prototype when the appraisal process commences. The system then responds by extracting feature parameters (IDs, types, dimensions) from building information model based on the specified mode which are exclusive in operation. Also, the system interacts with the accompanying database to call up corresponding information on costs, energy and emission factors. Other input information to be specified or confirmed by the designer at various stages along the time line include maintenance frequency, design life of structure, building area, life cycle boundary, sustainability indicator factors and weightings. Weightings are provided after the various design solutions have been assessed for their various sustainability credentials on life cycle cost, carbon footprint and ecological footprint. Some of the corresponding feedbacks from the system include display of extracted feature information and associated unit costs, initial cost estimation, calculation results of sustainability indicator measures and the desirability 
scores of the design options. The desirability scores provide numerical scaling of the performance of the design solutions to aid the designer on decisions concerning preferred options. The designer returns back to the BIMenable software environment when the programme of the appraisal system ends.

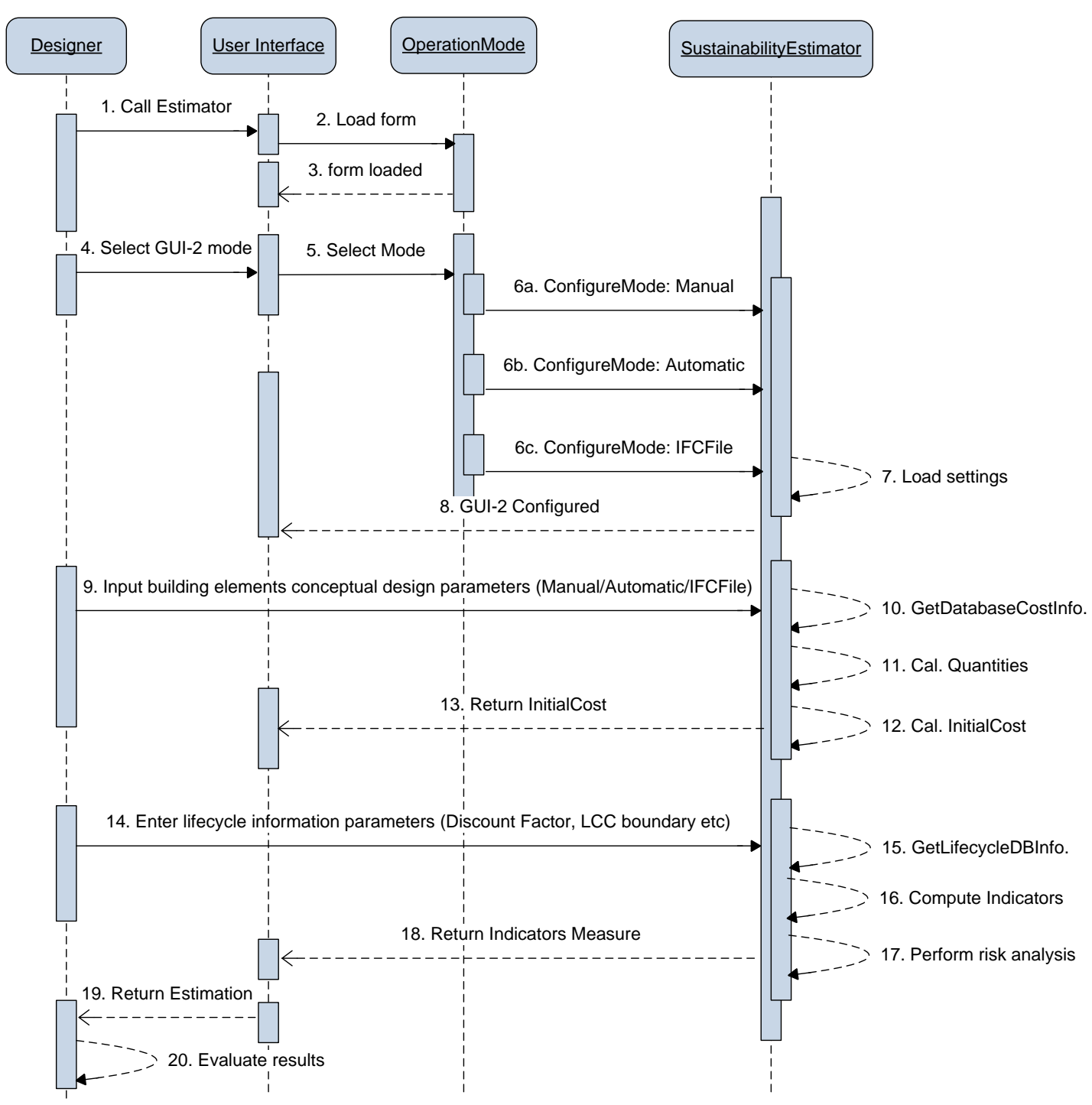

Figure 10: Sequence diagram of the sustainability model 


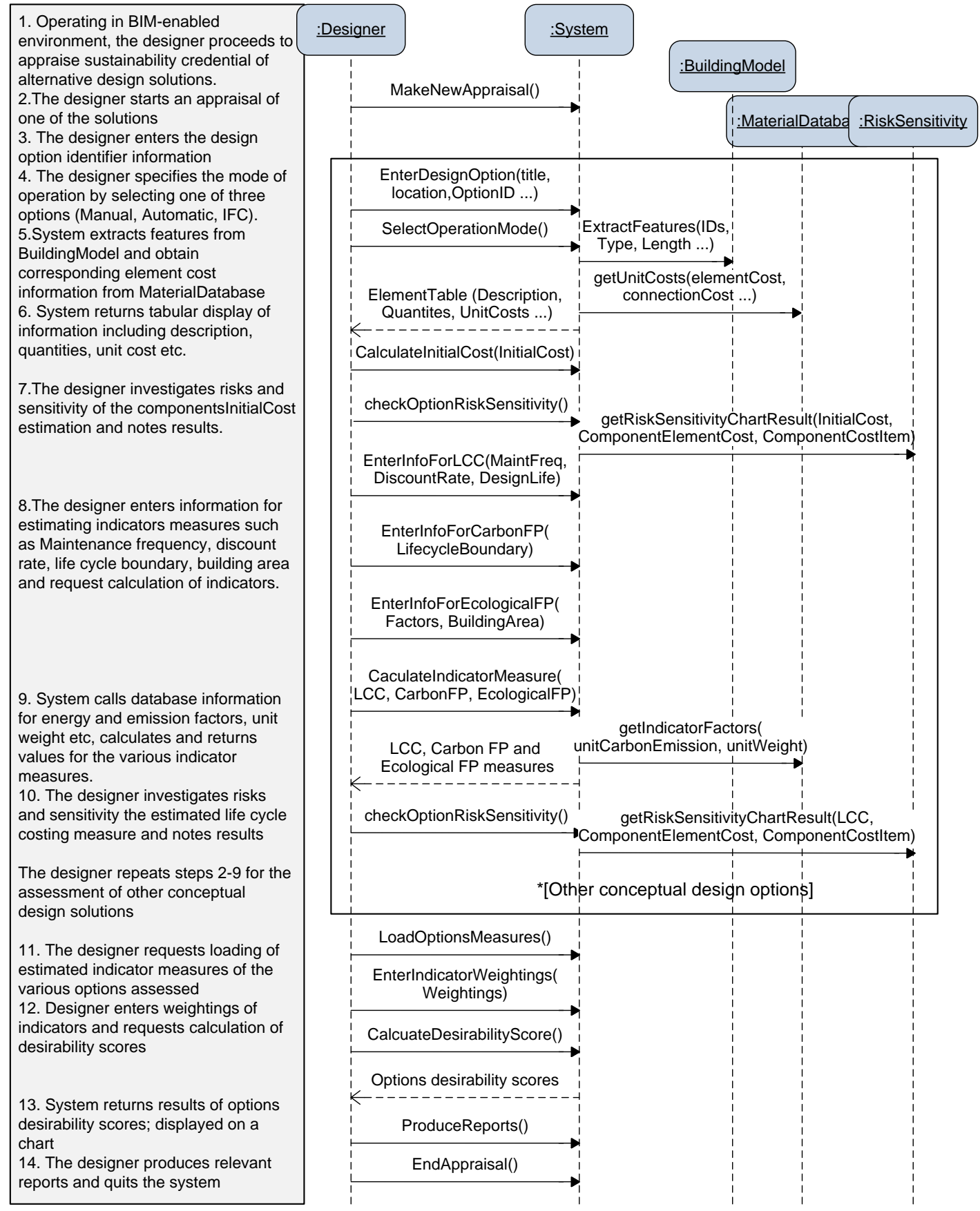

Figure 11: System sequence diagram of the prototype operation

\subsection{Prototype application scenario}

This section presents an illustration of the working of the prototype in a typical structural design activity. The aim is to show the efficacy of the proposed sustainability modelling framework in assisting designers to evaluate the sustainability score of conceptual design options based on lifecycle costing as the economic indicator, and environmental impacts relating to the atmosphere and biosphere. It helps create a basis for favouring a design solution above alternatives when selecting preferred options during design iterations. 


\subsubsection{Description of options and input data}

The project used for the case illustration is a hypothetical 3-storey office building framed in structural steel. The overall height of the structure is $12 \mathrm{~m}$ (from the foundation level to the soffit of the roof). It is $3.5 \mathrm{~m}$ (to allow services and air circulation) between floors and has a plan area of $30 \times 18 \mathrm{~m}$. The respective conceptual design options for the sustainability appraisal are shown in Figure 12. The alternative design options have similar input data on items such as: design life of structure; the building footprint or floor area; building surface area for cladding purposes, maintenance frequency for the various key elements; and discount rate for calculating corresponding net present values. However, the options vary in framing pattern (positioning of grids), floor type, type of cladding and materials used for roofing. Table 5 gives the details of the input data relating to the similarities and differences between the design options. The building footprint area has been kept equal for the alternative design solutions since structural framing options rarely change a building plan area which is usually dictated by the architect's design. In this illustration, openings in the floors such as for staircases have been ignored based on considerations that they will be similar for all options and therefore do not have any significant effect on the final output. Also, it is worth mentioning that cost related inputs are intended to demonstrate the efficacy of the prototype and not a reflection of current market values.

\subsubsection{Output sample and data analysis}

The prototype considers only the superstructure of a building for sustainability analysis since maintenance issues are not often associated with the substructure after construction is completed. The criteria used for evaluation are lifecycle costing, carbon footprint and ecological footprint. The components of the life cycle cost include the initial cost, maintenance, decommissioning cost and residual value. These are the key representative components of Equation 1 relevant for the estimation of the LCC of structural components in this work. Although a number of cost database exists, relevant materials price details have been obtained from the SPON's cost estimates [60]. Carbon footprint is currently calculated based on the embodied energy of the materials which have been sourced from Version 2.0 of the Inventory of Carbon \& Energy (ICE) [61]. Ecological footprint combines the measure of the built up land and the energy land of the structure design option. Figure 13 shows the sample output (Sustainability Index tab page) for the three conceptual design options. This tab page is preceded by six other tab pages; Material Selection, Initial Cost, Material Records, Cost Summary, Sustainability Parameters and Indicator Estimation designed for accepting and viewing inputs from the user as well as data abstracted from the building information model. The last tab page is Reporting Services where information generated from the sustainability model could be exported to a PDF file, Excel file or a Word file for record keeping or further analysis. Typically on the Sustainability Index tab page, the user loads the various alternative design solutions (three options in this case) and moves on to specify the respective weightings for combining the environmental performance indicators, carbon footprint and ecological footprint. The next set of weightings to specify is for economic and environment analysis. In both cases the default weightings have been set to 50\%:50\%. The final event on this tab page is to hit the specified button to generate a chart showing the sustainability score of the various options. As seen from the chart (details also given in Table 6), the sustainability (desirability) scores are $0.28,0.37$ and 0.35 for options 1, 2 and 3 respectively. This is obtained from applying the default weightings to the normalised values of the respective indicator measures based on principles of MCDA. The sustainability scores can be used by practitioners to appraise alternative conceptual design solutions of projects. The system provides the designer additional sustainability criteria, in the form of relative desirability scores, to constructability and structural integrity for favouring a particular design solution above alternatives. Since the scores are relative to the number of alternative solutions and unique for different projects, the comparison of such different projects by the system is not tenable. However, further research will be useful to develop a universal system where designs for different projects, irrespective of their differences, can be compared on a common sustainability scale. Results from such scales can be then be generally applied as structural sustainability design tags of projects subject to acceptability by the industry. 


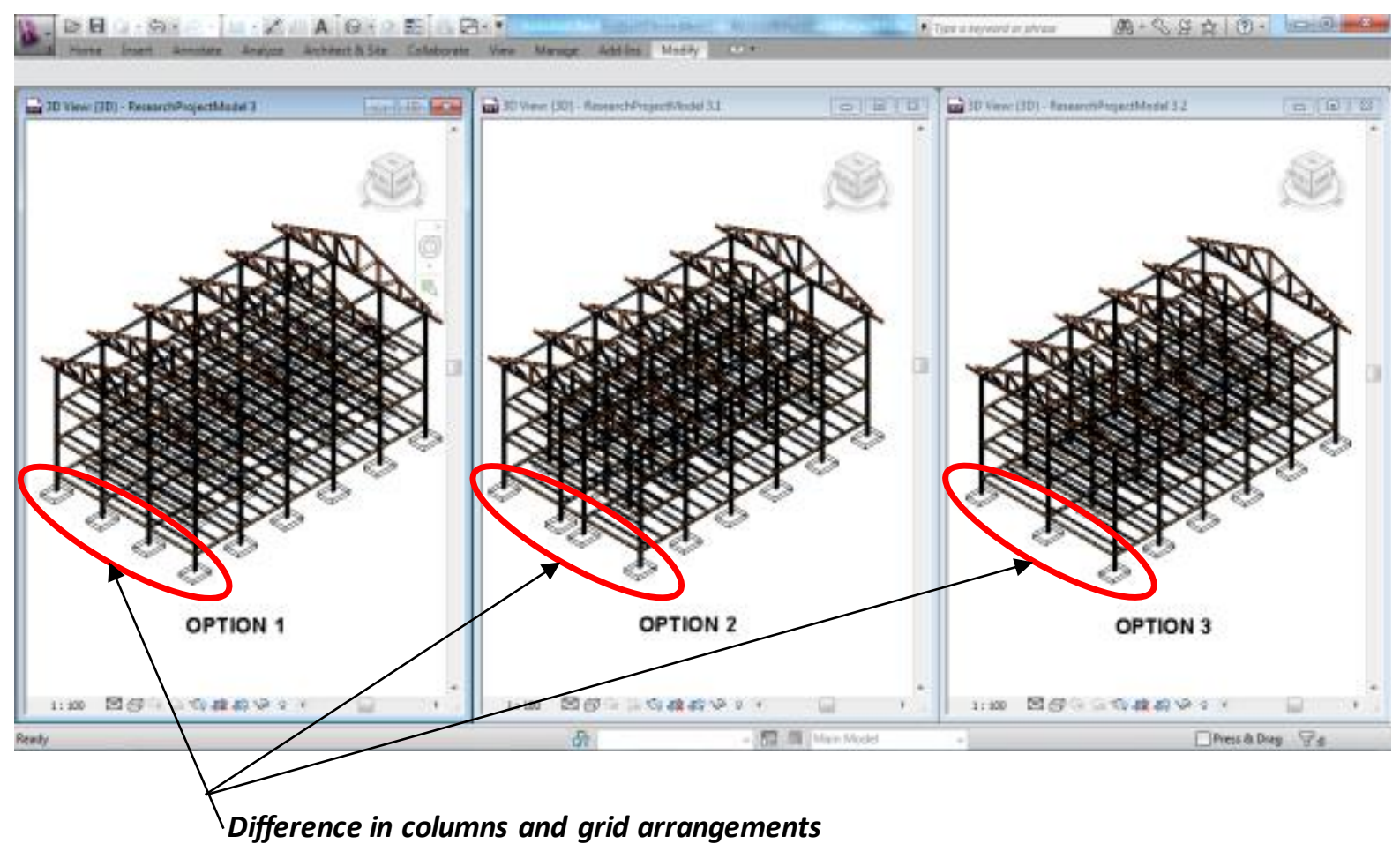

Figure 12: 3D Models of three alternative design solutions

Table 5: Input data for design options

\begin{tabular}{llll}
\hline Description & Option 1 & Option 2 & Option 3 \\
\hline Options similarities & & & \\
Design life $($ Yrs $)$ & 80 & 80 & 80 \\
Building floor area $\left(\mathrm{m}^{2}\right)$ & 540.00 & 540.00 & 540.00 \\
Building surface area $\left(\mathrm{m}^{2}\right)$ & 1344.00 & 1344.00 & 1344.00 \\
Cladding area $\left(\mathrm{m}^{2}\right)$ & 1008.00 & 1008.00 & 1008.00 \\
Maintenance frequency (Yrs) & 10 & 10 & 10 \\
Discount rate (\%) & 2 & 2 & 2 \\
Option differences & & & \\
Framing weight (t) & 85.84 & 82.47 & 74.00 \\
Floor Type & Metal decking & Insitu - concrete & $\begin{array}{l}\text { Precast concrete on } \\
\text { Cladding Type }\end{array}$ \\
Roof Material & Metal - aluminium & Metal-steel & Fibre cement \\
Grid spacing & Metal (aluminium) & Clay tiles & Concrete tiles \\
& @ 6m centres (3 & Grid @ 7.5m, & $\begin{array}{l}\text { Grid spacing @ 9m } \\
\text { centres (2 bays) }\end{array}$ \\
\hline
\end{tabular}

With respect to the MCDA principle, the ranking of the three options is: Option $2>$ Option $3>$ Option 1. That is, Option 2 has the highest sustainability score of 0.37 and it is therefore the preferred option in terms of sustainability of structural steel framing system. As evident in Table 6, within the scope of the prototype, Option 3 is closely ranked to Option 2. In the aspect of environmental sustainability, Option 3 is more favoured as it has the least measures of embodied energy, carbon footprint and ecological footprint while Option 2 is better in terms of the economic indicator of life cycle cost. On combining the 
economic and environmental aspects, Option 2 emerges as the most sustainable option when equal weightings of these measures are considered; however this situation might change if the ratios of the different sets of weightings are altered. To a large extent, specifying weightings of the various indicators rest in the hand of the designer or user which is influenced by his/her perception of the likely degree of impact associated with the various indicators. However, it is possible to create some uniformity in the application of these weightings if standardization is initiated by the concerned institutions. The ideal practice is that the allocation of weighting to criterion in decision frameworks should reflect preferences of the concerned decision makers as highlighted by Gühnemann et al. [62]. This is potentially a source of contention where there is no standard institutional guide for combining indicators in decision making. For the indicators used in this research, such guides have not been found and therefore a gap that needs to be tackled is emphasized in this paper.

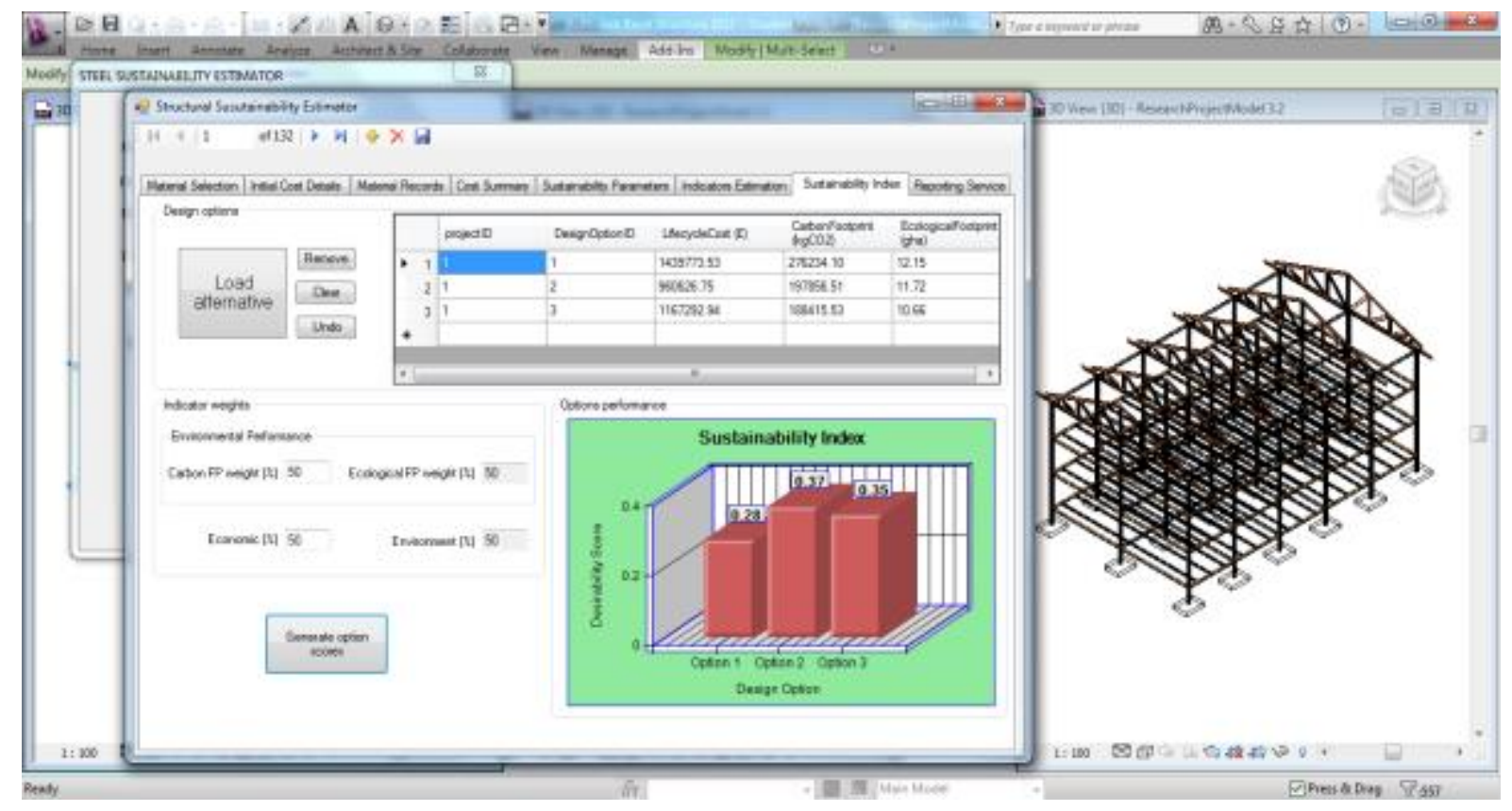

Figure 13: Output of sustainability analysis of design options

The prototype in this research was developed on the default basis of equal weightings of the indicators and sub-indicator categories. Although most composite indicators rely on equal weightings [63], there is some empirical basis for doing so in this research. The environment, carbon footprint and ecological footprint sub-indicators are complementary and measure two distinct important aspects of the environment: atmosphere and biosphere, respectively. These aspects are considered equally important in terms of impact. A correlation of carbon exists in the two indicators [64] but this does not affect the prototype results as the same condition is applied for all the considered design options. At the main indicator level, economy and environment also constitute two out of the three key (equally important) pillars of sustainable development. This is also reflected in the Building for Environmental and Economic Sustainability (BEES) approach in combining environment and economy to select cost-effective green products [65].

The choice of weighting factors for indicator measures is crucial in any assessment activity. To a great extent, it determines final assessment results and is a key source for subjectivity [66]. The basis for deriving the weightings and the effects of the weighting process on the interpretation of outputs are the two critical subjective issues. Weightings may be determined on based on questions on whether effects from sustainability impacts are reversible, long lasting, and widely-spread in terms of population or area but more importantly on the selection of final end points reflecting the potential impact of the environmental components in question. For example, weightings should not be based on whether air pollution is more important than land pollution but instead on which of these aspect exerts a greater specific potential impact on the environment as an end point of concern. As the relationships between buildings/building components and their associated sustainability impacts keep advancing through 
research and requisite data collection, it will become possible to establish reliable guides to assist users apply weighting protocols to assessment criteria and to meaningfully interpret aggregated results [67].

Table 6: Components of the sustainability analysis output for design options

\begin{tabular}{llll}
\hline Description & Option 1 & Option 2 & Option 3 \\
\hline Economic & & & \\
Initial Cost (£) & 827,056 & 744,867 & 671,568 \\
Maintenance cost (£) & $1,328,750$ & $1,115,625$ & $1,315,210$ \\
Decommissioning cost (£) & 10,733 & 10,671 & 10,514 \\
Residual value (£) & 1,474 & 1,416 & 1,270 \\
Life cycle cost (£) & $2,165,066$ & $1,869,747$ & $1,996,022$ \\
Environmental & & & \\
Embodied energy (GJ) & 3,662 & 2,191 & 2,162 \\
Carbon footprint (kgCO 2$)$ & 181,970 & 100,849 & 113,558 \\
Built-up Land (gha) & 1.36 & 1.36 & 1.36 \\
Energy Land (gha) & 10.79 & 10.37 & 9.30 \\
Ecological Footprint (gha) & 37.7 & 22.7 & 22.6 \\
& & & \\
Sustainability Score & $\mathbf{0 . 2 8}$ & $\mathbf{0 . 3 7}$ & $\mathbf{0 . 3 5}$ \\
\hline
\end{tabular}

\section{IMPLEMENTATION FEATURES AND SIGNIFICANCE}

The main features the implementation work of this research stem from the need for the consideration of profession-specific building features, requirements for modelling associated sustainability implications and the use object-oriented methodology of process mapping and feature instantiations. Some of these features and their significance are briefly described.

\section{- Process model and object based-instantiations for BIM extension}

This research work presents requisite information modelling representations needed for bolting-on an object-oriented application to an existing BIM platform. It applied the feature mapping and extraction principle to select relevant building elements for intended analysis to be further performed. This is perhaps the most important feature of this research work. It demonstrates that a number of $\mathrm{n}$ dimensional building performance measures other than sustainability could be bolted-on to existing BIM-enabled platforms. This means that in the near future, as the scope of BIM becomes clearer, researchers will be able to use similar principles to implement needed BIM extensions.

\section{- Profession-specific feature extraction}

For holistic sustainable construction in the AEC industry, a case for profession-specific sustainability pursuance was established in this work. The implementation focused the extraction of structural engineering-related elements for sustainability analysis. The same approach can be applied for other professions.

\section{- Requirement guide for sustainability modelling}

Two groups of requirement guide feature in the implementation prototype. The first group is the appraisal factors which include time, boundary limits, material flows and functional unit. The second group concerns software implementation issues such as generality, flexibility, formality, ease-of-use and scalability. These issues have been handled in a combination of approaches using programming algorithms, relational database implementations and taking advantage of the object-oriented features of C\#. Statistic-based algorithms such as Monte Carlo applications and multi-criteria decision analysis 
were employed in implementing aspects relating to exploring what-if-scenarios of material combinations and the performance risk and sensitivity analysis. Also, appropriate programming references and namespaces such as XML and RDL-based Schemas were included in the implementation works.

\section{- Simplification of sustainability indicators}

The issue of using different and numerous indicators has been a challenge in sustainability assessment across the world. This does not only make the process cumbersome but also presents difficulties in comparing results from various existing assessment tools. Based on the relevance to the structural domain in building construction, the research featured a simplification of indicators into three measures: LCC, Carbon Footprint and Ecological Footprint. These indicators cover the economic and environmental aspect of sustainability deemed to be of more significant influence on structural design decision. The indicators constitute elements in a conceptual sustainability modelling framework used to implement the structural sustainability estimator prototype.

\section{CONCLUSION}

Sustainability requirements in construction have warranted the need for structural engineers to become better informed on the best performed design solution, in terms of sustainability, among alternatives. BIM presents opportunities for integrating the modelling of sustainability performance into the early stages of building design. This paper discussed an integrated framework, based on the feature modelling technique to depict the sustainability of the structural engineer's conceptual design of steel-framed building. The case illustration and associated descriptions presented in this paper give the key steps in the operation of the sustainability modelling prototype. It targets the fulfilment of the implementation requirements of being generic, formal, flexible, scalable, and time-efficient.

The construction sector has been recognised to have a substantial influence on sustainable development both in terms of positive and negative impacts. The growing concerns to reduce the negative impacts have been a driver in sustainability research innovations and strategies. One of such research areas has been the development and optimization decision support systems to aid professionals in making better informed decisions while and when it matters most to effect changes. Hence, this work is targeted at the conceptual design stage and currently looking at structural steel framing systems. Further area of work will be extending the prototype to other structural framing systems such as reinforced concrete and to be able to consider different shapes of building geometry. Modalities for extension to other existing BIM platforms remain another interesting area for further investigation. Standardization of sustainability indicator weightings in construction application is also worth consideration.

Finally, the research concludes that the utilized process and data modelling techniques can be employed to model sustainability related information to inform decisions right from the early stages of structural design. As demonstrated in this work, design decision support systems can be optimized to include sustainability credentials through the use of object-based process and data modelling techniques. The work presents a sustainability appraisal framework, associated implementation algorithms and related object mappings and representations systems that could be used to achieve decision support optimization to assist structural engineers in early design stages.

\section{References}

1. Kohler, N. and Moffatt, S., Life cycle analysis of the built environment, in Sustainable building and construction. 2003, UNEP industry and Environment. p. 17-21.

2. Ding, G.K.C., Sustainable construction-role of environmental assessment tools. Environment and Management, 2008. 86: p. 451-464.

3. Uher, T. Absolute indicators of sustainable construction. 1999: RICS.

4. BIM-IWG, BIM Management for value, cost and carbon improvement, in A report for the Government Construction Client Group, BIM Working Party Strategy Paper. 2011, BIM Industry Working Group (BIM-IWG).

5. Haapio, A. and Viitaniemi, P., A critical review of building environmental assessment tools. Environmental impact assessment review, 2008. 28(7): p. 469-482. 
6. Scheuer, C., Keoleian, G.A., and Reppe, P., Life cycle energy and environmental performance of a new university building: modeling challenges and design implications. Energy and Buildings, 2003. 35(10): p. 1049-1064.

7. Reap, J., Roman, F., Duncan, S., and Bras, B., A survey of unresolved problems in life cycle assessment. The International Journal of Life Cycle Assessment, 2008. 13(5): p. 374-388.

8. Zhang, J., Webster, A., Lawrence, M., Nepal, M., Pottinger, R., Staub-French, S., and Tory, M., Improving the usability of standard schemas. Information Systems, 2011. 36(2): p. 209-221.

9. Cruz, C., Building Information Modeling, in A report of LAB. Le2i. 2008, Université de Bourgogne.

10. NIBS, National Building Information, Modeling Standards Part-1: Overview, Principles and Methodologies. 2007, US National Institute of Building Sciences Facilities Information Council, BIM Committee.

11. Lee, A., Wu, S., and Aouad, G., nD modelling: the background in Constructing the future: $n D$ modelling, G. Aouad, A. Lee, and S. Wu, Editors. 2006, Taylor and Francis.

12. Zhang, J. and Hu, Z., BIM-and 4D-based integrated solution of analysis and management for conflicts and structural safety problems during construction: 1. Principles and methodologies. Automation in Construction, 2011. 20(2): p. 155-166.

13. Ruppel, U. and Schatz, K., Designing a BIM-based serious game for fire safety evacuation simulations. Advanced Engineering Informatics, 2011. 25: p. 600-611.

14. Tizani, W. and Mawdesley, M.J., Advances and challenges in computing in civil and building engineering. Advanced Engineering Informatics, 2011. 25: p. 569-572.

15. Zhang, S., Teizer, J., Lee, J.-K., Eastman, C.M., and Venugopal, M., Building information modeling (BIM) and safety: automatic safety checking of construction models and schedules. Automation in Construction, 2013. 29: p. 183-195.

16. Tang, P., Huber, D., Akinci, B., Lipman, R., and Lytle, A., Automatic reconstruction of as-built building information models from laser-scanned point clouds: A review of related techniques. Automation in Construction, 2010. 19(7): p. 829-843.

17. Motawa, I. and Almarshad, A., A knowledge-based BIM system for building maintenance. Automation in Construction, 2013. 29: p. 173-182.

18. Kim, K. and Teizer, J., Automatic design and planning of scaffolding systems using building information modeling. Advanced Engineering Informatics, 2014.

19. Ding, L., Zhou, Y., and Akinci, B., Building Information Modeling (BIM) application framework: The process of expanding from $3 D$ to computable $n D$. Automation in Construction, 2014.

20. Nguyen, T., Shehab, T., and Gao, Z., Evaluating Sustainability of Architectural Designs Using Building Information Modeling. Open Construction and Building Technology Journal, 2010. 4: p. 1-8.

21. Nepal, M.P., Staub-French, S., Pottinger, R., and Zhang, J., Ontology-based feature modeling for construction information extraction from a building information model. Journal of Computing in Civil Engineering, 2012. 27(5): p. 555-569.

22. Brunetti, G. and Golob, B., A feature-based approach towards an integrated product model including conceptual design information. Computer-Aided Design, 2000. 32(14): p. 877-887.

23. Staub-French, S. and Nepal, M.P., Reasoning about component similarity in building product models from the construction perspective. Automation in Construction, 2007. 17(1): p. 11-21.

24. Staub-French, S., Fischer, M., Kunz, J., Ishii, K., and Paulson, B., A feature ontology to support construction cost estimating. AI EDAM, 2003. 17(2): p. 133-154.

25. Staub-French, S., Fischer, M., Kunz, J., and Paulson, B., A generic feature-driven activity-based cost estimation process. Advanced Engineering Informatics, 2003. 17(1): p. 23-39.

26. Wang, H.-H. and Boukamp, F., Ontology-based representation and reasoning framework for supporting job hazard analysis. Journal of Computing in Civil Engineering, 2011. 25(6): p. 442-456.

27. Ergan, S.K. and Akinci, B., Automated Approach for Developing Integrated Model-Based Project Histories to Support Estimation of Activity Production Rates. Journal of Computing in Civil Engineering, 2011. 26(3): p. 309-318.

28. Motavalli, S., Cheraghi, S., and Shamsaasef, R., Feature-based modeling; An object oriented approach. Computers \& industrial engineering, 1997. 33(1-2): p. 349-352.

29. Shah, J.J. and Rogers, M., Functional requirements and conceptual design of the feature-based modelling system. Computer-Aided Engineering Journal, 1988. 5(1): p. 9-15.

30. van Leeuwen, J. and de Vries, B. Capturing design knowledge in formal concept definitions. in Proceedings of the 5th Conference on Design and Decision Support Systems in Architecture and Urban Planning, Nijkerk, The Netherlands. 2000.

31. Van Leeuwen, J.P. and Wagter, H. Architectural design-by-Features. in Proceedings of the 7th International Conference on Computer Aided Architectural Design Futures held in Munich, Germany. 1997: Kluwer Academic Publishers, Dordrecht.

32. van Leeuwen, J.P., Wagter, H., and Oxman, R.M. Information modelling for design support-a Feature-based approach. in Proceedings of the 3rd Conference on Design and Decision Support Systems in Architecture and Urban Planning, Spa, Belgium. 1996. 
33. Oti, A.H. and Tizani, W. A sustainability extension for building information modelling in Proceedings of the CIB W78 2012: 29th International Conference -Beirut, Lebanon, 17-19 October. 2012. Beirut, Lebanon: CIB MENA.

34. Ortiz, O., Castells, F., and Sonnemann, G., Sustainability in the construction industry: A review of recent developments based on LCA. Construction and Building Materials, 2009. 23: p. 28-39.

35. Reed, R., Bilos, A., Wilkinson, S., and Schulte, K.-W., International comparison of sustainable rating tools. The journal of sustainable real estate, 2009. 1(1): p. 1-22.

36. Singh, R.K., Murty, H., Gupta, S., and Dikshit, A., Development of composite sustainability performance index for steel industry. Ecological Indicators, 2007. 7(3): p. 565-588.

37. Kloepffer, W., Life cycle sustainability assessment of products. The International Journal of Life Cycle Assessment, 2008. 13(2): p. 89-95.

38. Oti, A.H. and Tizani, W. A Sustainability Appraisal Framework for the Design of Steel-Framed Buildings. in Proceedings of the Thirteenth International Conference on Civil, Structural and Environmental Engineering Computing. 2011. Crete, Greece: Civil-Comp Press, Stirlingshire, United Kingdom,.

39. Sarma, K. and Adeli, H., Life cycle cost optimization of steel structures. International Journal for Numerical Methods in Engineering, 2002. 55(12): p. 1451-1462.

40. Wiedmann, T. and Minx, J., A definition of'carbon footprint'. ISA Research Report, 2007. 1.

41. Rawlinson, S. and Weight, D., Sustainability: embodied carbon., in Building Magazine. 2007, David Langdon Global Consultants. p. 88-91.

42. Wackernagel, M., Monfreda, C., Schulz, N.B., Erb, K.H., Haberl, H., and Krausmann, F., Calculating national and global ecological footprint time series: resolving conceptual challenges. Land use policy, 2004. 21(3): p. 271-278.

43. Mateus, R. and Bragança, L., Sustainability assessment and rating of buildings: Developing the methodology SBTool $\langle$ sup $>$ $P T</$ sup $>-H$. Building and Environment, 2011. 46(10): p. 1962-1971.

44. Oti, A.H., Building information modelling for sustainability appraisal of conceptual design of steel-framed buildings, in Civil Engineering. 2014, University of Nottingham, Nottingham, United Kingdom.

45. BRE. Environmental Impact Assessment and Whole Life Cost - EnVest 2. 2012 [cited 201214 November];

]. Available from: http://envest2.bre.co.uk/account.jsp\#.

46. Sturge, K., European Property Sustainability Matters-Benchmark Tools and Legal Requirements. 2009, London.

47. Staub-French, S., Fischer, M., Kunz, J., Ishii, K., and Paulson, B., A feature ontology to support construction cost estimating. AI EDAM: Artificial Intelligence for Engineering Design, Analysis and Manufacturing, 2003. 17(02): p. 133-154.

48. Nuseibeh, B. and Easterbrook, S., Requirements engineering: a roadmap, in Proceedings of the Conference on The Future of Software Engineering. 2000, ACM: Limerick, Ireland.

49. Zowghi, D. and Coulin, C., Requirements elicitation: A survey of techniques, approaches, and tools, in Engineering and managing software requirements. 2005, Springer. p. 19-46.

50. Geyer, P. and Buchholz, M., Parametric systems modeling for sustainable energy and resource flows in buildings and their urban environment. Automation in Construction, 2012. 22: p. 70-80.

51. Ugwu, O., Kumaraswamy, M., Kung, F., and Ng, S., Object-oriented framework for durability assessment and life cycle costing of highway bridges. Automation in Construction, 2005. 14(5): p. 611-632.

52. Lippiatt, B.C., Selecting cost-effective green building products: BEES approach. Journal of Construction Engineering and Management, 1999. 125(6): p. 448-455.

53. Yeo, S., Mak, M., and Balon, S., Analysis of decision-making methodologies for desirability score of conceptual design. Journal of Engineering Design, 2004. 15(2): p. 195-208.

54. Norris, G.A. and Marshall, H.E., Multiattribute decision analysis method for evaluating buildings and building systems. 1995: Building and Fire Research Laboratory, National Institute of Standards and Technology.

55. Ashworth, A., Estimating the life expectancies of building components in life-cycle costing calculations. Structural Survey, 1996. 14(2): p. 4-8.

56. Amar, J.G., The Monte Carlo method in science and engineering. Computing in science \& engineering, 2006. 8(2): p. 9-19.

57. Kwak, Y.H. and Ingall, L., Exploring Monte Carlo simulation applications for project management. Risk Management, 2007. 9(1): p. 44-57.

58. BS ISO 15686-5, Buildings and constructed assets - Service-life planning - Life-cycle costing. 2008, British Standard.

59. Larman, C., Applying UML and patterns: An Introduction to object-oriented analysis and design and iterative develop. 2005: Prentce-Hall.

60. Langdon, D., ed. SPON's Civil Engineering and Highway Works Price Book 26th ed., ed. D. Langdon. 2012, SPON Press.

61. Hammond, G. and Jones, C., Inventory of Carbon \& Energy (ICE) Version 2.0, Sustainable Energy Research Team (SERT) University of Bath, Editor. 2011: Bath. 
62. Gühnemann, A., Laird, J.J., and Pearman, A.D., Combining cost-benefit and multi-criteria analysis to prioritise a national road infrastructure programme. Transport Policy, 2012. 23: p. 15-24.

63. Giovannini, E., Handbook on constructing composite indicators: methodology and user guide. 2008, OECD.

64. Galli, A., Wiedmann, T., Ercin, E., Knoblauch, D., Ewing, B., and Giljum, S., Integrating Ecological, Carbon and Water footprint into a "Footprint Family" of indicators: Definition and role in tracking human pressure on the planet. Ecological Indicators, 2012. 16: p. 100-112.

65. Lippiatt, B.C. and Boyles, A.S., Using BEES to select cost-effective green products. The International Journal of Life Cycle Assessment, 2001. 6(2): p. 76-80.

66. Cole, R.J., Building environmental assessment methods: redefining intentions and roles. Building Research \& Information, 2005. 33(5): p. 455-467.

67. Cole, R.J., Building environmental assessment methods: clarifying intentions. Building Research \& Information, 1999. 27(4-5): p. 230-246. 